\title{
The relationship between carbon and nitrogen metabolism in cucumber leaves acclimated to salt stress
}

\author{
Marcin Robert Naliwajski ${ }^{\text {Corresp., }}{ }^{1}$, Maria Skłodowska ${ }^{1}$ \\ ${ }^{1}$ Department of Plant Physiology and Biochemistry, Faculty of Biology and Environmental Protection, University of Lodz, Lodz, Poland \\ Corresponding Author: Marcin Robert Naliwajski \\ Email address: marcin.naliwajski@biol.uni.lodz.pl
}

The study examines the effect of acclimation on carbon and nitrogen metabolism in cucumber leaves subjected to moderate and severe $\mathrm{NaCl}$ stress. The levels of glucose, sucrose, NADH/NAD ${ }^{+}-\mathrm{GDH}, \mathrm{AspAT}$, AlaAT, NADP+-ICDH, G6PDH and 6GPDH activity were determined after 24 and 72 hour periods of salt stress in acclimated and non-acclimated plants. Although both groups of plants showed high Glc and Suc accumulation, they differed with regard to the range and time of accumulation. Acclimation to salinity decreased the activities of $\mathrm{NADP}^{+}-\mathrm{ICDH}$ and deaminating NAD+-GDH compared to controls; however, these enzymes, together with the other examined parameters, showed elevated values in the stressed plants. The acclimated plants showed higher G6PDH activity than the non-acclimated plants, whereas both groups demonstrated similar 6PGDH activity. The high activities of NADH-GDH, AlaAT and AspAT observed in the examined plants could be attributed to a high demand for glutamate. The observed changes may be required for the maintenance of correct TCA cycle activity, and acclimation appeared to positively influence these adaptive processes. 
1 The relationship between carbon and nitrogen metabolism in cucumber leaves acclimated to salt

2 stress

3 Marcin Robert Naliwajski* and Maria Skłodowska

4 Department of Plant Physiology and Biochemistry, Faculty of Biology and Environmental

5 Protection, University of Lodz, Poland

6 *Corresponding author: e-mail marcin.naliwajski@biol.uni.lodz.pl, tel. +48 4263544 18, fax. +48

$7 \quad 426354423$

8

9 Abstract

The study examines the effect of acclimation on carbon and nitrogen metabolism in cucumber leaves subjected to moderate and severe $\mathrm{NaCl}$ stress. The levels of glucose, sucrose, $\mathrm{NADH} / \mathrm{NAD}^{+}-\mathrm{GDH}, \mathrm{AspAT}, \mathrm{AlaAT}, \mathrm{NADP}{ }^{+}-\mathrm{ICDH}, \mathrm{G} 6 \mathrm{PDH}$ and 6GPDH activity were determined after 24 and $72 \mathrm{~h}$ periods of salt stress in acclimated and non-acclimated plants. Although both groups of plants showed high Glc and Suc accumulation, they differed with regard to the range and time of accumulation. Acclimation to salinity decreased the activities of $\mathrm{NADP}^{+}$ICDH and deaminating $\mathrm{NAD}^{+}-\mathrm{GDH}$ compared to controls; however, these enzymes, together with the other examined parameters, showed elevated values in the stressed plants. The acclimated plants showed higher G6PDH activity than the non-acclimated plants, whereas both groups demonstrated similar 6PGDH activity. The high activities of NADH-GDH, AlaAT and AspAT observed in the examined plants could be attributed to a high demand for glutamate. The observed changes may be required for the maintenance of correct TCA cycle activity, and acclimation appeared to positively influence these adaptive processes.

Abbreviations: AlaAT - alanine aminotransferase; AspAT - aspartate aminotransferase; G6PDH - glucose-6-phosphate dehydrogenase; GDH - glutamate dehydrogenase; Glc - glucose; GS/GOGAT - glutamine synthetase/glutamate synthase cycle; ICDH - isocitrate dehydrogenase, OPPP - oxidative pentose phosphate pathway; 2-OxG - oxoglutarate; 6PGDH - 6phosphogluconate dehydrogenase; Pro - proline; ROS - reactive oxygen species; Suc - sucrose; TCA - tricarboxylic acid

\section{Introduction}


32 Soil salinization is an environmental stress factor that can limit growth, development and 33 productivity of plants (Bartels \& Dinakar, 2013; Roychoudhury et al., 2015). A range of strategies

have been proposed for the development of NaCl-tolerant plants. One potential tool is based on the in vitro development and isolation of $\mathrm{NaCl}$-tolerant cell/callus lines by Agrobacteriummediated transformation. Alternatively, $\mathrm{NaCl}$ seed priming and/or seedling conditioning can be used to increase the capacity of plants to adapt to salinity. Such low NaCl concentration pretreatments have been shown to improve seed germination, seedling emergence and plant growth under saline conditions for a range of crop plants. The favorable effects associated with $\mathrm{NaCl}$ pretreatments have been observed to persist in later development stages such as fruiting and seed production in many plants (Hossain et al., 2007; Sivritepe et al., 2008).

In plants, $\mathrm{NaCl}$ stress has a strong influence on nitrogen and carbon metabolism, and this is reflected in a number of changes occurring in a range of physiological and biochemical processes (Ashraf \& Harris, 2004; Anjum et al., 2017). Plants can cope with salt stress by synthesizing such osmolytes as proline (Pro), soluble sugars and amines, and the osmoprotectant activities of these compounds in have been well examined in higher plants (Muchate et al., 2016, Negrão et al., 2017). Sugars, especially glucose (Glc) and sucrose (Suc), play a crucial role in plant metabolism. They supply carbon and energy, but also participate in the signaling pathway initiating the upregulation of defence-related genes and down-regulation of photosynthetic gene expression (Gibson, 2000; Mhamdi et al., 2010; Leterrier et al., 2012, 2016). In a wide range of plants, total carbohydrate content increases after $\mathrm{NaCl}$ treatment, mainly due to elevated Suc and Glc levels (Singh et al., 2015).

Under salinity stress, Suc and Glc accumulation allows active osmotic adjustment, thus facilitating adaptation by sodium translocation and compartmentation, and by influencing protein turnover and compatible solute production (Singh et al., 2015). There is strong evidence that glucose and fructose play a role during the relief period (Liu \& van Staden 2001).

High $\mathrm{NaCl}$ levels can also influence plant metabolism by interfering with steps in nitrogen assimilation, thus reducing the nitrogen level in the plant (Flores et al., 2004; Debouba et al., 2006; 2007). Apart from the legume family, most higher plants fix nitrogen by first reducing its inorganic form $\left(\mathrm{NO}_{3}{ }^{-}\right)$to $\mathrm{NH}_{4}{ }^{+}$and then incorporating it into an organic form (Oliveira et al., 2009; Hachiya \& Sakakibar, 2017). This process takes place via two pathways, the first is the glutamine synthetase/glutamate synthase (GS/GOGAT) cycle, yielding glutamine and glutamate (Glu) 
63 (Miflin \& Habash, 2002, Liu \& von Wirén, 2017), and the other is the glutamate dehydrogenase 64 (GDH, EC 1.4.1.2) pathway; this catalyzes the amination of 2-oxoglutarate (2-OxG) or reversible deamination of glutamate, and requires NADH or NAD ${ }^{+}$coenzymes, respectively (Wang et al., 2014). GDH is mainly located in mitochondria but some evidence suggests that it is also present in the cytosol (Terce-Laforgue et al., 2004, 2013; Fontaine et al., 2006). NADH-GDH plays a crucial role in ammonium detoxification because GDH displays greater aminating activity at higher levels of $\mathrm{NH}_{4}{ }^{+}$(Frechilla et al., 2002; Wang et al., 2014). NAD-GDH has been proposed to play a role in the deamination of glutamate under stress and during senescence (Bechtold et al., 1998).

The tricarboxylic acid (TCA) cycle is the main source of carbon skeletons required for $\mathrm{NH}_{4}^{+}$ assimilation, and is linked to amino acid metabolism by glutamate dehydrogenase (Hodges, 2002, Terce-Laforgue et al., 2013). The TCA cycle thus links carbon and nitrogen metabolisms: organic acids originating from glycolysis are oxidised and directly exported as 2-OxG, which are required for $\mathrm{NH}_{4}{ }^{+}$assimilation and for forming the main carbon skeletons for amino acid synthesis (NunesNesi et al., 2013). NAD-GDH triggers the oxidation of Glu to 2-OxG, which may enter the TCA cycle; these play a significant role in the delivery of carbon skeletons when their amount is limited (Nunes-Nesi et al., 2013, Liu \& von Wirén, 2017). 2-OxG, an important keto-acid of the TCA cycle, plays a central role in amino acid formation and nitrogen transport (Zhang et al., 2009). Isocitrate dehydrogenase (ICDH) and aspartate aminotransferase (AspAT, EC 2.6.1.1) are both sources of 2-OxG (Reda, 2015). While the ICDH pathway allows for net glutamate synthesis via the GS/GOGAT cycle, the AspAT pathway results in the synthesis of aspartate instead of glutamate, and requires oxaloacetate as carbon-skeleton input (Gálvez et al., 1999; Forde \& Lea 2007). Eukaryotic cells possess two forms of isocitrate dehydrogenase with different cofactor specificity: i.e. $\mathrm{NAD}^{+}\left(\mathrm{NAD}^{+}-\mathrm{ICDH}, \mathrm{EC}\right.$ 1.1.1.41) or $\mathrm{NADP}^{+}\left(\mathrm{NADP}^{+}-\mathrm{ICDH}, \mathrm{EC}\right.$ 1.1.1.42). Both forms of the enzyme catalyze the reversible oxidative decarboxylation of isocitrate to form 2-OxG. In plants, the $\mathrm{NAD}^{+}-\mathrm{ICDH}$ isoform is a TCA cycle enzyme located in the mitochondrial matrix (Douce \& Neuburger 1989) whereas $\mathrm{NADP}^{+}-\mathrm{ICDH}$ is located in the cytosol, mitochondria, plastids and peroxisomes (Chen, 1998; Corpas \& Barroso 2018; Gálvez et al., 1999). Approximately $80-95 \%$ of the total ICDH activity in leaf tissues depends on NADP ${ }^{+}-\mathrm{ICDH}(\mathrm{Chen}$ \& Gadal 1990). By supplying the cytosol with 2-OxG as a primary acceptor for $\mathrm{NH}_{4}^{+}$assimilation, 
93 ICDH is hypothesized to play a key role in the synthesis and export of amino acids, and to be a 94 link between $\mathrm{C}$ and $\mathrm{N}$ metabolism (Fieuw et al., 1995).

95

Besides 2-OxG production, $\mathrm{NADP}^{+}-\mathrm{ICDH}$ is believed to be involved in supplying the cytosol with NADPH (Podgórska et al., 2013; Hodges, 2002) which is required for the reduction of $\mathrm{NO}_{3}{ }^{-}$or for many other biosynthesis pathways in cytosol and plastids (Kruger \& von Schaewen 2003). This role is supported by the oxidative pentose phosphate pathway (OPPP). Two OPPP enzymes, i.e. glucose-6-phosphate dehydrogenase (G6PDH, EC 1.1.1.49) and 6-phosphogluconate dehydrogenase (6PGDH, EC 1.1.1.44), were found in the cytosol, plastids, and peroxisomes (Corpas \& Barroso 2018). G6PDH, a rate-limiting enzyme of the OPPP, oxidizes glucose-6phosphate into 6-phosphoglucono- $\delta$-lactone and reduces $\mathrm{NADP}^{+}$to $\mathrm{NADPH}$, whereas 6-PGDH oxidizes 6-phosphoglucono- $\delta$-lactone into ribulose-6-phosphate and produces a second molecule of NADPH (Kruger \& von Schaewen 2003; Singh \& Srivastava 2014). In higher plants, the major form of G6PDH is a cytosolic isoform representing 80-95\% of total cellular activity, with the remaining $5-20 \%$ of the total activity being performed by the chloroplastic or plastidic isoform (Cardi et al., 2013).

Glutamate is a central intermediate of nitrogen metabolism (Forde \& Lea 2007), and acts as a substrate for the synthesis of amino acids (arginine, proline and glutamine), nucleotides, chlorophyll and glutathione (Martinez-Andújar et al., 2013). There is strong evidence that salt stress increases the activity of the enzymes involved in the Glu metabolism, including the aminotransaminases engaged in the production of all protein amino acids, except proline. Glu is a major amino group donor for the alanine aminotransferase (AlaAT, EC 2.6.1.2) and AspAT functions (Jha \& Dubey, 2004). Reactions catalyzed by aminotransferases are reversible; alanine and aspartate may also participate in the replenishment of the Glu pool (Forde \& Lea, 2007). Agricultural productivity is severely affected by soil salinity across wide areas of land. According to United Nations Food and Agriculture Organization statistics FAO (http:// faostat.fao.org), one of the most widely-cultivated vegetables is the cucumber. In Poland alone, cucumber and gherkin cultivation in 2014 encompassed 16,552 ha of land with total production being 538057 tones; this value was the highest since 1963. Despite this importance, cucumber plants are characterized by low resistance to various stress conditions especially salinization. 
122 It is important that plants can maintain a correct $\mathrm{N}: \mathrm{C}$ ratio, and to achieve this, various biochemical

123 processes have developed. These processes enable the plant to adjust its metabolism and 124 accommodate environmental stress conditions (Coruzzi \& Zhou, 2001).

125 The aim of the present study was to assess the ability of cucumber plants to acclimatize to $\mathrm{NaCl}$

126 stress by evaluating the changes of nitrate and carbon metabolism associated with this process. To 127 this end, the study examines a range of parameters in cucumber leaves taken from stressed plants 128 which had been either acclimated or non-acclimated to salinity stress: NADH/NAD ${ }^{+}-G{ }^{2}$, 129 AspAT, AlaAT and NADP + -ICDH, G6PDH, 6GPDH activity, and proline, Glc and Suc level were 130 measured $24 \mathrm{~h}$ and $72 \mathrm{~h}$ after being subjected to moderate and severe $\mathrm{NaCl}$ stress in the two groups 131 of plants.

132

133 Materials and methods

134 Materials

135 Cucumber (Cucumis sativus L.) cv. "Cezar" plants were grown in a growth chamber at a 136 temperature of $23^{\circ} \mathrm{C}$ with $16 \mathrm{~h} \mathrm{light} / 8 \mathrm{~h}$ dark photoperiod with $350 \mu \mathrm{E} \mathrm{m} \mathrm{m}^{-2} \mathrm{~s}^{-1}$ light intensity and $13760-70 \%$ relative humidity. Five-week-old plants with four fully-expanded leaves were used. Two 138 groups of cucumber plants were used in the study: one group that had been acclimated to salt stress 139 (AP) by fourfold treatment with $20 \mathrm{mM} \mathrm{NaCl}$ at seven-day intervals, and another group that had 140 not (NAP). Finally all groups were stressed with $100 \mathrm{mM} \mathrm{NaCl}$ (moderate stress) (NAP-100, AP$100)$ and $150 \mathrm{mM} \mathrm{NaCl}$ (severe stress) (NAP-150, AP-150). The activities of NADH/NAD ${ }^{+}-G D H$, AspAT, AlaAT and NADP ${ }^{+}-\mathrm{ICDH}$ G6PDH and 6GPDH, and the levels of proline, Glc and Suc were examined $24 \mathrm{~h}$ and $72 \mathrm{~h}$ after moderate and severe stress application.

\section{Methods}

\section{Enzyme extract preparation}

147 Fresh leaf tissue $(0.5 \mathrm{~g})$ was homogenized in a mortar at $4{ }^{\circ} \mathrm{C}$ in $2.5 \mathrm{~cm}^{3}$ of medium: $50 \mathrm{mM}$ Tris$148 \mathrm{HCl}$ buffer $\left(\mathrm{pH}\right.$ 7.6) containing $1 \mathrm{mM} \mathrm{MgCl}_{2}, 1 \mathrm{mM}$ EDTA, $1 \mathrm{mM}$ DTT, $0.5 \%$ PVP 149 (polyvinylpyrrolidone) and $10 \mathrm{mM} \beta$-mercaptoethanol. The homogenate was centrifuged at 20000 $150 g$ for 20 minutes at $4^{\circ} \mathrm{C}$. The supernatant was used to determine NADH/NAD ${ }^{+}-\mathrm{GDH}_{\text {, AspAT, }}$

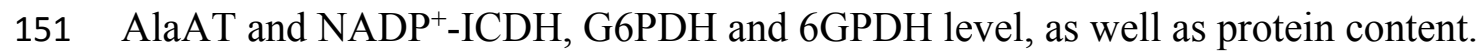




\section{Glutamate dehydrogenase enzyme assay}

154 GDH activity was assayed spectrophotometrically at $30^{\circ} \mathrm{C}$ by monitoring the oxidation of NADH 155 (aminating GDH activity, NADH-GDH) or reduction of NAD (deaminating GDH activity, NAD ${ }^{+}$$156 \mathrm{GDH})\left(\varepsilon=6.22 \mathrm{mM}^{-1} \mathrm{~cm}^{-1}\right)$ at $340 \mathrm{~nm}$ according to Groat \& Vance (1981). For NADH-GDH 157 activity, the reaction mixture $\left(2 \mathrm{~cm}^{3}\right)$ consisted of $0.1 \mathrm{M}$ Tris- $\mathrm{HCl}$ buffer, $\mathrm{pH} 8.0$, enzyme extract, $15811 \mathrm{mM}$ 2-oxoglutaric acid, $0.1 \mathrm{M} \mathrm{NH} 4 \mathrm{Cl}$, and $0.2 \mathrm{mM} \mathrm{NADH}$. For NAD ${ }^{+}-\mathrm{GDH}_{\text {activity the }}$ 159 reaction mixture $\left(2 \mathrm{~cm}^{3}\right)$ consisted of $0.1 \mathrm{M}$ Tris- $\mathrm{HCl}$ buffer, $\mathrm{pH} 8.8$, enzyme extract, $80 \mathrm{mM} \mathrm{L-}$ 160 glutamic acid, and $0.7 \mathrm{mM} \mathrm{NAD}^{+}$. The enzyme activity was expressed in units, each representing 161 the amount of enzyme catalyzing the oxidation/reduction of $1 \mathrm{nmol} \mathrm{NADH} / \mathrm{NAD}$ per minute and 162 expressed in $\mathrm{U} \mathrm{mg}^{-1}$ protein.

163

\section{Aminotransferase enzyme assay}

AlaAT and AspAT activities were measured spectophotometrically according to de Sousa \& Sodek (2003). AlaAT activity was assayed in the alanine-pyruvate direction by coupling the reaction with NADH oxidation by lactate dehydrogenase. The reaction mixture $\left(2 \mathrm{~cm}^{3}\right)$ consisted of 0.1 M Tris- $\mathrm{HCl}$ buffer, $\mathrm{pH}$ 7.5, 0.5 M L-alanine, $15 \mathrm{mM}$ 2-oxoglutarate, 0.18 mM NADH, five units of lactate dehydrogenase and enzyme extract. AspAT activity was assayed in the aspartateoxaloacetate direction by coupling the reaction with NADH oxidation by malate dehydrogenase. The reaction mixture $\left(2 \mathrm{~cm}^{3}\right)$ consisted of $0.1 \mathrm{M}$ Tris-HCl buffer $\mathrm{pH}$ 7.8, $5 \mathrm{mM}$ EDTA, 0.2 M Laspartate, $12 \mathrm{mM}$ 2-oxoglutarate, $0.18 \mathrm{mM} \mathrm{NADH}$, five units of malate dehydrogenase and enzyme extract. AlaAT and AspAT activities were calculated using the absorption coefficient for NADH $\left(\varepsilon=6.22 \mathrm{mM}^{-1} \mathrm{~cm}^{-1}\right)$ and expressed in units, each representing the amount of enzyme catalyzing the formation of $1 \mathrm{nmol}$ of product per minute and expressed in $\mathrm{U} \mathrm{mg}^{-1}$ protein.

\section{$\mathrm{NADP}^{+}$-dependent isocitrate dehydrogenase enzyme assay}

$\mathrm{NADP}^{+}$-ICHD activity was measured spectophotometrically at $25^{\circ} \mathrm{C}$ by monitoring the reduction of NADP $\left(\varepsilon=6.22 \mathrm{mM}^{-1} \mathrm{~cm}^{-1}\right)$ at $340 \mathrm{~nm}$ according to Canino et al. (1996). The reaction medium $\left(2 \mathrm{~cm}^{3}\right)$ contained the following: $0.05 \mathrm{M}$ Tris- $\mathrm{HCl}, \mathrm{pH} 8.0,0.6 \mathrm{mM} \mathrm{NADP}^{+}, 1 \mathrm{mM} \mathrm{MgCl}_{2}, 9.6 \mathrm{mM}$ isocitrate as a starter of reaction. The enzyme activity was expressed in units, each representing the amount of enzyme catalyzing the reduction of $1 \mathrm{nmol} \mathrm{NADP}^{+}$per minute and expressed in $\mathrm{U}$ $\mathrm{mg}^{-1}$ protein. 


\section{Glucose-6-phosphate and 6-phosphogluconate dehydrogenase enzyme assay}

186

187

188

189

190

191

192

193

194

195

196

197

198

199

200

201

202

203

204

205

206

207

208

209

210

211 Statistical analysis

212

213

\section{Sugar determinations} analyses.

\section{Proline determination}

\section{Protein determinations}

Dehydrogenase activity was assayed spectrophotometrically at $30^{\circ} \mathrm{C}$ by monitoring the reduction of $\mathrm{NADP}^{+}\left(\varepsilon=6.22 \mathrm{mM}^{-1} \mathrm{~cm}^{-1}\right)$ at $340 \mathrm{~nm}$ according to Sgherri et al. (2002). For G6PDH activity, the reaction mixture $\left(2 \mathrm{~cm}^{3}\right)$ consisted of $0.05 \mathrm{M}$ Tris- $\mathrm{HCl}$ buffer $\mathrm{pH} 7.7$, enzyme extract, $10 \mathrm{mM}$ $\mathrm{MgCl} 2 ; 0.25 \mathrm{mM} \mathrm{NADP}^{+}$and $2 \mathrm{mM} \mathrm{G6P}$ as a starter of reaction. For 6PGDH activity the reaction mixture $\left(2 \mathrm{~cm}^{3}\right)$ consisted of $0.05 \mathrm{M}$ Tris- $\mathrm{HCl}$ buffer $\mathrm{pH} 7.7$, enzyme extract, $10 \mathrm{mM} \mathrm{MgCl} 2 ; 0.25$ $\mathrm{mM} \mathrm{NADP}^{+}$and $2 \mathrm{mM} 6 \mathrm{PG}$ as a reaction starter. The enzyme activity was expressed in units, each representing the amount of enzyme catalyzing the reduction of $1 \mathrm{nmol} \mathrm{NADP}^{+}$per minute and expressed in $\mathrm{U} \mathrm{mg}^{-1}$ protein.

Glc and Suc contents were determined in the extracts obtained from leaf samples $(0.5 \mathrm{~g} \mathrm{FW})$ after triple $80 \%$ ethanol extraction. The ethanolic extracts were evaporated to dryness at $50^{\circ} \mathrm{C}$ and the residue was resolubilized with distilled water. The concentrations of both sugars were assayed using commercial enzymatic test (Boehring Mannheim) according to the manufacturer's instructions and expressed in $\mu \mathrm{g}$ per mg protein determined in the extract used for enzyme activity

Free proline content was determined using the ninhydrin method (Bates et al., 1973). The proline concentration was estimated in reference to a standard curve for L-proline and expressed in micromoles per milligram protein

Protein content was measured according to Bradford (1976) using BSA as a standard.

The significance of differences between mean values was determined by the nonparametric MannWhitney Rank Sum Test using Statistica 13 software. Differences at $\mathrm{P}<0.05$ were considered 
214 significant. Data are given as mean values \pm standard deviation. Each data point is the mean of

215 four independent experiments $(n=4)$ and one plant per treatment was analyzed in each experiment.

216

\section{Result}

218 Activity of aminating glutamate dehydrogenase (NADH-GDH)

219 The results showed that acclimation did not significantly influence NADH-GDH activity (Fig.

220 1A). Moreover, the activity demonstrated in the non-acclimated and acclimated plants changed to

221 a similar degree under both $\mathrm{NaCl}$ stress levels. These changes were observed mainly $72 \mathrm{~h}$ after

222 moderate and severe stress application. NADH-GDH activity increased by about $200 \%$ in the

223 NAP-100 and NAP-150 groups compared to NAP, and by 208\% (AP-100) and 348\% (AP-150)

224 compared to AP.

225 Activity of deaminating glutamate dehydrogenase (NAD-GDH)

226 Contrary to NADH-GDH activity, the acclimation process influenced the deaminating activity of

227 GDH (Fig. 1B). GDH activity in the non-stressed plants was significantly lower in the acclimated

228 then in the non-acclimated ones after both 24 and 72 h. After stress application, NAD ${ }^{+}-G_{D H}$

229 activity increased to a greater degree in the acclimated plants: the activity was 52\% higher for AP-

230150 than AP after $24 \mathrm{~h}$, and 137\% higher after $72 \mathrm{~h}$.

231 Activity of aminotransferases

232 In the non-stressed variants, no differences were found between the acclimated and non-acclimated

233 plants for either aminotransferase (Figs. 2A and 2B). However, the difference appeared after stress

234 application. In the non-acclimated plants, AlaAT activity decreased by about $25 \%$ after $24 \mathrm{~h}$

235 following moderate salt stress (NAP-100) compared to NAP (Fig. 2A); however, no further

236 significant change in enzyme activity was observed for NAP-100 or NAP-150 after prolonged

237 exposure $(72 \mathrm{~h})$. However, differences in AlaAT activity were observed in the acclimated plants:

238 Enzyme activity was found to be about 70-80\% greater in AP-100 and AP-150 than in AP at $72 \mathrm{~h}$

239 after exposure.

240 No change in AspAT activity was observed between the AP and NAP groups at $24 \mathrm{~h}$ (Fig. 2B). In

241 contrast, after $72 \mathrm{~h}$, while only moderate stress (NAP-100) increased AspAT activity in the non-

242 acclimated plants (23\% higher than NAP), both types of stress (AP-100 and AP-150) increased

243 AspAT activity in the acclimated plants (around 70\% higher than AP). 
245 Activity of $\mathrm{NADP}^{+}$-dependent isocitrate, glucose-6-phosphate and 6-phosphogluconate 246 dehydrogenases

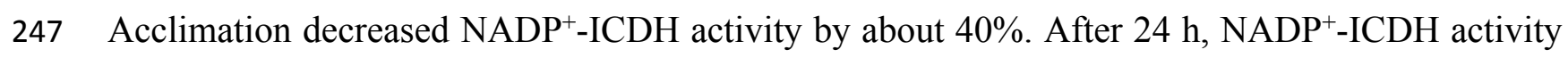
248 increased by about 63\% (AP-100) and 70\% (AP-150) compared to AP, but no such increase was 249 observed in non-acclimated plants. However, after 72 h, NADP ${ }^{+}$-ICDH activity was higher in 250 NAP-100 (46\%) and NAP-150 (122\%) compared to NAP, and higher in AP-100 (27\%) and in AP$251150(80 \%)$ than in AP (Fig. 3C).

252 The acclimation process influenced the activity of G6PDH. Moreover, acclimation influenced 253 plant response to salt stress. After $24 \mathrm{~h}$, increases in G6PDH activity were observed only in the 254 non-acclimated plants: 48\% (NAP-100) and 24\% (NAP-150) compared with NAP. Following 255 prolonged stress (72 h), both NAP and AP showed enhanced G6PDH activity, but these increases 256 were greater in acclimated plants; however, while this activity was 120\% higher in NAP-100 and 257 98\% higher in NAP-150 compared to NAP, these levels were about 200\% higher in AP-100 and 258 AP-150 compared to AP. Stress application induced significant changes in 6PGDH activity in both 259 groups of cucumber plants at $72 \mathrm{~h}$ (Fig. 3A), being significantly higher in each stressed group than 260 its respective non-stressed group. In addition, in acclimated plants, this activity was higher than in 261 non-acclimated ones: 6PGDH activity was about 30\% higher in NAP-100 than NAP but about $26270 \%$ higher in AP-100 and AP-150 than in AP.

\section{Glucose and sucrose concentrations}

264 The process of acclimation significantly influenced the constitutive Glc concentration in the 265 studied variants, NAP and AP (Fig. 4A). Glc level was more than two to four times higher in the 266 AP group than the NAP group. Following salt stress, Glc concentrations increased significantly 267 after $24 \mathrm{~h}$ and were about three times higher in NAP-100 and NAP-150 than in NAP. Two days 268 later $(72 \mathrm{~h})$, these values increased to twelve times higher in NAP-100 and NAP-150 compared to 269 NAP. Similarly, in the plants acclimated to stress, the AP-100 and AP-150 Glc concentrations 270 increased by $50 \%$ and $71 \%$, respectively, in comparison to AP after $24 \mathrm{~h}$; these levels further 271 increased to $85 \%$ and 51\% for AP-100 and AP-150, respectively, compared to AP after $72 \mathrm{~h}$.

272 Similarly to Glc, sucrose concentration was found to be two- to threefold higher in AP than NAP. 273 Following stress, greater changes were observed after 72 h. Interestingly, in NAP-100, salt stress 274 caused a progressive increase in Suc concentration, rising from almost twice higher than NAP after $27524 \mathrm{~h}$ to twenty-times higher after $72 \mathrm{~h}$. In response to the severe stress (NAP-150) Suc 
276 concentration increased significantly, being eighteen-fold higher in comparison to NAP after $72 \mathrm{~h}$

277 (Fig. 4B). A high level of Suc accumulation was observed in the acclimated plants, but only after

$27872 \mathrm{~h}$; however, after this time, Suc concentration increased in all exposed groups, being four-fold

279 higher in AP-100 and twelve-fold higher in AP-150 compared to AP values.

280 Proline content

281 The acclimation process significantly influenced proline content (Fig. 4C). Constitutive Pro level 282 was 20-35\% lower in AP than in NAP; however, this value increased during the experiment, 283 reaching its highest concentration $72 \mathrm{~h}$ after stress treatment. After $24 \mathrm{~h}$, both acclimated and non284 acclimated plants demonstrated a significant increase in free proline level after severe stress 285 treatment compared to respective controls (63\% for NAP-150 and 49\% for AP-150). After 72 h, 286 Pro level was 395\% higher in NAP-100 and 496\% higher in NAP-150 compared to NAP, and $287308 \%$ higher in AP-100 and 395\% higher in AP-150 compared to AP.

288

289

290

\section{Discussion}

291 Salt stress is associated with the accumulation of compatible solutes such as carbohydrates, and 292 this is generally considered to be an adaptive response to salinization (Roitsch, 1999). A high level 293 of carbohydrates inhibits the expression of genes coding for photosynthesis enzymes, including 294 those of the Calvin cycle (Couee et al., 2006).

295 In our study, the accumulation of soluble carbohydrates (Glc and Suc) was observed after stress 296 (Fig, 4A, 4B). It should be noted that while both carbohydrates were initially present in higher 297 amounts in the acclimated plants, a smaller increase in sugar levels was observed in the acclimated 298 plants than the non-acclimated ones following exposure, and that the two carbohydrates 299 accumulated at different rates: Glc concentration increased early ( $24 \mathrm{~h})$ in all stressed groups, 300 whereas Suc accumulation varied according to acclimation, stress intensity and time of exposure. 301 It should be noted that the highest Suc level was observed with the lowest Glc level only in AP302150 after $72 \mathrm{~h}$. This might indicate that in the acclimated plants, severe stress led to reverse 303 regulation of these carbohydrates and enhanced direct utilization of Suc in adaptive processes. 304 Previous studies indicate that contrary to Glc, Suc is an effective osmoprotectant (Singh et al., 305 2015, Sami et al., 2016). 
306

307

308

309

310

311

312

313

314

315

316

317

318

319

320

321

322

323

324

325

326

327

328

329

330

331

332

333

334

335

336

Acclimation decreased $\mathrm{NADP}^{+}-\mathrm{ICDH}$ activity, which suggests that this enzyme is highly susceptible to salinity stress. However, in both groups of plants (NAP and AP) the NADP ${ }^{+}$-ICDH activity was found to be enhanced during the later phase $(72 \mathrm{~h})$ of the experiment, but was lower in AP than in NAP. This reduction in $\mathrm{NADP}^{+}-\mathrm{ICDH}$ activity associated with acclimation might result from salt-triggered inhibition of aconitase, which supplies a substrate for isocitrate dehydrogenase by salt-induced generation of ROS, especially $\mathrm{H}_{2} \mathrm{O}_{2}$ (Zhang et al., 2009). The cytosolic isoform of $\mathrm{NADP}^{+}-\mathrm{ICDH}$ is an important $\mathrm{NADP}^{+}$reducing enzyme, and together with OPPP enzymes, replenishes the pool of NADPH. Besides fuelling NADPH-dependent enzymes e.g. in proline synthesis, the NADPH produced by mitochondrial and chloroplastic ICDH activity might be important for glutathione regeneration used in inter alia the ascorbate-glutathione cycle and glutathione peroxidase system (Gálvez \& Gadal, 1995; Corpas \& Barroso, 2014), both of which are involved in ROS scavenging in mitochondria, chloroplasts and cytosol (Hodges et. al, 2003). Liu et al. (2010) showed that in transgenic Arabidopsis thaliana, over-expression of cytosolic $\mathrm{NADP}^{+}-\mathrm{ICDH}(\mathrm{ZmICDH})$ induced by drought and salt stress boosted salt tolerance.

Accumulation of soluble sugars under salt stress is known to enhance free Pro content (Hellmann et al., 2000). Proline accumulation ameliorates the damaging effect of salt stress by functioning as an osmoprotectant in a similar way to Suc. However, it remains undecided whether its protective influence is due to the direct scavenging of reactive oxygen species (ROS) (Hayat et al., 2012, Signorelli et al., 2016). Pro has been found to contribute to the scavenging of $\mathrm{OH}$ by a Pro-Pro cycle without consumption of Pro, and not to quench singlet oxygen (Signorelli et al., 2014). In addition, proline accumulation increases under saline conditions but is not a direct scavenger of peroxinitrite, superoxide, nitrogen oxide or dioxide (Signorelli et al., 2013, 2016). However, high Pro accumulation might have a negative influence on a cell, possibly leading to protein denaturation (Hayat et al., 2012) and changes in mitochondria and chloroplast ultrastructure, and may also initiate the early steps of programmed cell death (Deuschle et al., 2004). Although proline concentration was found to increase in both stressed groups, Pro concentration was lower in the acclimated plants. Zhang et al. (2009) report that disrupted functioning of mitochondria influences carbon and nitrogen metabolism and cellular biosynthesis. This disruption may decrease TCA cycle activity and disturb ATP production. Salt stress leads $i . a$ to changes in the profiles of organic acids which are mainly produced in the TCA cycle (López-Bucio et al., 2000). Moreover, as malate stimulates nitrate uptake by the root (Touraine et al., 1992), demand for malic acid is enhanced 
337 when nitrogen is limited by salinity. As malate is synthesized via malate dehydrogenase from

338 oxaloacetate and NADH in the presence of $\mathrm{NAD}^{+}$, it is another process which might influence the 339 activity of the TCA cycle (van Dongen et al., 2011). Generally, reduced TCA cycle activity

340

341

342

343

344

345

346

347

348

349

350

351

352

353

354

355

356

357

358

359

360

361

362

363

364

365

366 activates a fermentation processes which leads, among others, to an accumulation of alanine via a reversible reaction converting pyruvate and glutamate to alanine and 2-OxG; the process is catalyzed by AlaAT. As the formed 2-OxG may enter into the TCA cycle, AlaAT activity facilitates the production of ATP (van Dongen et al., 2011). However, alanine synthesis is not the sole cause of AlaAT induction (de Sousa \& Sodek, 2003): As reversible transamination reactions are controlled by substrate and product level, it is possible that a rapid increase in pyruvate or depletion of 2-OxG could also be responsible (de Sousa \& Sodek, 2003). Although AP and NAP demonstrated similar AspAT and AlaAT levels, changes were observed under stress situations (Fig. 2A, 2B): In acclimated plants, similar increases in AspAT and AlaAT activity were observed in AP-100 and AP-150 after $72 \mathrm{~h}$, while in non-acclimated plants, AlaAT activity decreased in NAP-100 and NAP-150 after $24 \mathrm{~h}$, and AspAT increased only in NAP-100 after $24 \mathrm{~h}$.

In the acclimated plants, the glutamate-producing AlaAT and AspAT processes seem to play an important role in the replenishment of the glutamate pool. Glutamine is not only engaged in the assimilation and release of ammonia, it is also a substrate in proline synthesis. Our results indicated that increases in AlaAT, AspAT and aminating GDH activities correlated with the growth of free proline level. In many plant species, Pro accumulation associated with salt stress has been correlated with stress tolerance, and its concentration is generally higher in salt-tolerant plants than in salt-sensitive ones (Szabados \& Savoure, 2010). Free proline level has previously been found to correlate with high vigour in acclimated suspension cell cultures subjected to salinization (Naliwajski \& Skłodowska, 2014).

Our present data indicates that free proline level in leaf tissues increased in response to salt stress, especially in the late phase of the experiment. The presence of fewer salt-induced injury symptoms in the acclimated plants, such as the presence of chlorotic spots on the leaf surface, yellowing starting at the leaf tips and margins and working back to the vein and wilting (Fig. $5 \& 6$ ), might be associated with an elevated concentration of sucrose, which is a better osmoprotectant than glucose (Rejšková et al., 2007; Keunen et al., 2013; Singh et al., 2015). Degl’Innocenti et al. (2009) 
367 report that Hordeum maritimum showed a lower reduction of growth under saline conditions 368 compared to Hordeum vulgare, indicating substantial salt tolerance.

369 The production and accumulation of organic solutes is one of the important physiological 370 responses demonstrated by plants to salinity; however, it is an energy-consuming process which 371 decreases growth. Pérez-López et al. (2009) report that the observed decrease in plant growth 372 resulted not only from the toxic effect of ions, but also from poor water relations under salt stress.

373 The lower level of Pro observed in the acclimated plants compared to non-acclimated ones 374 following salt stress might be associated with the use of glutamate, a substrate for proline synthesis, 375 to other metabolic processes i.a. synthesis of arginine (Arg) which acts as a major nitrogen storage 376 compound in higher plants. Moreover, arginine, together with ornithine, may also act as a 377 precursor of polyamines, which play an important role in plant stress tolerance (Forde \& Lea, 378 2007). The fact that the level of Pro was lower in stressed AP than in stressed NAP may result 379 from its possible metabolism to prolinebetaine and hydroxyprolinebetaine in AP: the two 380 compounds are more potent osmoprotectants than proline. Research on related species with 381 different capacities for prolinebetaine and hydroxyprolinebetaine accumulation strongly indicates

382

383

384

385

386

387

388

389

390

391

392

393

394

395

396

397 that the free proline pool size is inversely related to the total pool of the two compounds (Snight 1999). The lower concentration of proline observed in the acclimated plants than in the nonacclimated ones cannot be connected with its enzymatic degradation or a decrease in the activity of proline synthesis enzymes (Szabados \& Savoure, 2010). The changes observed in AlaAT activity in the non-acclimated cucumber plants show that the TCA cycle might be disturbed, and that under stress, NADH-GDH and AspAT are mainly engaged in the synthesis of glutamate. Kumar et al. (2000) report that aminating GDH activity rose with increasing salt stress in salttolerant rice (Oryza sativa L.) cultivars. This is in agreement with our present results (Fig. 1A), which indicate that NADH-GDH activity grew in both examined groups of plants in response to salt stress.

The enhanced activity of NADH-GDH observed in both acclimated and non-acclimated plants 72 $\mathrm{h}$ after $\mathrm{NaCl}$ application suggests not only a high demand for glutamate but also the presence of a significant amount of ammonium in the cells. Under stressful conditions, including salinity, NADH-GDH can play an important role in the detoxification of ammonium originating from the degradation of organic nitrogen compounds in response to stress, as well as in the replenishment of the pool of glutamate; this acts as a substrate in the synthesis of proline, which significantly 
398

399

400

401

402

403

404

405

406

407

408

409

410

411

412

413

414

415

416

417

418

419

420

421

422

423

424

425

426

427

428

accumulates in salt-stressed plants (Frechilla et al., 2002; Lasa et al., 2002). Similarly to NADHGDH, deaminating GDH activity was also enhanced in the acclimated cucumber leaves under severe salt stress conditions. Moreover, the simultaneous increase in NAD ${ }^{+}-G D H$ activity, which catalyzes the deamination of glutamate, could also be a source of ammonium ions, as well as of 2OxG in these organs. Bechtold et al. (1998) indicate that the GDH-mediated deamination of glutamate to ammonium and 2-OxG to be very important, particularly in plants under stress conditions and during senescence.

The lack of changes in $\mathrm{NAD}^{+}-\mathrm{GDH}$ activity observed in the non-acclimated plants in response to moderate and severe stress is in agreement with the results described by Debouba et al. (2006), who report that deaminating GDH activity greatly decreased with increasing $\mathrm{NaCl}$ concentration in tomato leaves and roots. Our analysis of deaminating GDH activity in the stressed acclimated and non-acclimated plants revealed differences in the regulation of cellular $\mathrm{NH}_{4}{ }^{+}$concentration; however, increased $\mathrm{NAD}^{+}-\mathrm{GDH}$ activity might also result from the need to replenish the limited pool of carbon skeletons, which is directly connected with the difference in $\mathrm{C} / \mathrm{N}$ status. Jha and Dubey (2004) suggest that GDH isoenzymes might be differentially induced depending on stressful conditions or according to the availability of $\mathrm{NH}_{4}{ }^{+}$. Therefore, in the leaves exposed to salinity, some of the GDH isoforms can be induced in the direction of ammonium assimilation and others in the direction of deamination. At the end of our experiment, both NADH- and NAD ${ }^{+}$ GDH activities were substantially increased in the leaves of cucumber plants exposed to salinity. This is consistent with the parallel enhancement of amination and deamination of GDH observed in plants treated with heavy metals (Kwinta \& Kolik, 2006; Gajewska \& Skłodowska, 2009).

It is probable that these changes in $\mathrm{GDH}$ activity take place in $\mathrm{NaCl}$ stressed plants. Acclimation did not influence G6PDH and 6PGDH activities, but the levels of both enzymes increased in both groups under stress conditions. However, in the acclimated plants, significant increases in both enzymes were observed only in the later phase of experiment $(72 \mathrm{~h})$, whereas in the non-acclimated plants, G6PDH activity was increased at $24 \mathrm{~h}$ while 6PGDH changed after another two days (72 h) (Fig. 3A, 3B). These findings indicate a demand for the reduced form of NADPH in the stressed non-acclimated plants from the beginning of the experiment, and that this demand continued to grow, to satisfy a demand for this nucleotide later on. Moreover, under stress conditions, higher activities of G6PDH and 6PGDH were observed in the acclimated cucumber plants than in the non-acclimated plants; this may indicate that the reduced pool of G6PDH was replenished more 
429 quickly in the AP plants. Upon exposure to salt, the cytosolic G6PDH activity and transcript level 430 may increase in order to support the syntheses of cofactors or intermediates involved in the 431 tolerance mechanisms (Nemoto et al., 2000; Del Santo et al., 2012). G6PDH activity has also been 432 found to be enhanced by an increase in ammonium assimilation (Bowsher et al., 1992; Esposito et 433 al., 2001). G6PDH activity was detected in both cytosol and plastids but the changes in G6PDH 434 activity observed in the present study were limited to the cytosol: to obtain the supernatant, it was 435 436 necessary to use reduced dithiothreitol, which inactivates the plastid isoform but not the cytosolic isoform (Asai et al., 2011). G6PDH controls carbon flow in the pentose phosphate pathway and produces reducing equivalents in the form of NADPH which are used i.a. in the antioxidant pathways (Corpas \& Barroso, 2016, 2018).

The oxidative damage induced by salt stress increased NADPH synthesis by OPPP; it can be hypothesized that the need to maintain a steady-state level of $\mathrm{H}_{2} \mathrm{O}_{2}$ in cells during stress would make hydrogen peroxide function as a signal enhancing G6PDH expression and activity (Liu \& van Staden 2001, Valderrama et al., 2006). Under our experimental conditions, the activities of G6PDH and 6PGDH were significantly enhanced in the leaves of both examined groups of plants. A similar response was reported in other plant species: In two-week-old wheat (Triticum aestium

L. cv. Chinese Spring) seedlings, the level of G6PDH transcripts rapidly increased within two $h$ 446 of $\mathrm{NaCl}$ treatment and reached peak expression after $12 \mathrm{~h}$ (Nemoto \& Sasakuma, 2000). During 447 prolonged $\mathrm{NaCl}$ stress, this expression fell below baseline level, indicating that G6PDH was involved in the initial responses of salt-stressed plants. However, salinity stress can cause a contrary response in other plant species: Zhang et al. (2013) found G6PDH activity to be 450 downregulated in salt-stressed suspension cultures of rice cells. Moreover, both NADPdehydrogenase activities were diminished in tomato root (Manai et al. 2014).

452 The changes in Glc and Suc levels as well as NADP ${ }^{+}-\mathrm{ICDH}_{\text {, AlaAT }}$ and AspAT activities might 453 indicate that after salinity stress, both groups of cucumber activated the responses. Under $\mathrm{NaCl}$ stress, the cells began processes that yielded intermediates for the anaplerotic reaction of the TCA cycle. Production of oxaloacetate from pyruvate catalyzed by AlaAT, transamination of aspartate 456 to oxaloacetate by AspAT and production of 2-OxG from glutamate by $\mathrm{NAD}^{+}-\mathrm{GDH}$, the most 457 458 important physiological anaplerotic reactions producing intermediates for the TCA cycle, additionally yield the reduced form of NADH (van Dongen et al., 2011). 
459 The observed accumulation of Glc and Suc levels did not result from more effective photosynthesis 460 due to the influence of osmotic stress and the presence of the toxic $\mathrm{Na}^{+}$ion derived from the $\mathrm{NaCl}$ 461 stress (Rejšková et al., 2007). Moreover, salinity stress would also decrease photosynthetic activity 462 because it would reduce the uptake of nitrogen compounds, and $\mathrm{CO}_{2}$ assimilation is related to the 463 nitrogen status of the leaf (Coruzzi \& Zhou, 2001; Cruz et al., 2003, Li et al., 2013). The observed 464 increases in the Glc and Suc levels were another factor which caused feedback inhibition of carbon 465 assimilation (Foyer, 1988).

466 Taken together, the accumulation of carbohydrates under stress conditions seems to result from 467 changes in their usual metabolism and/or their remobilization from storage pools. Our findings 468 suggest that the acclimation of cucumber plants to $\mathrm{NaCl}$ stress has a positive function because it 469 may prevent the destabilization of the cell respiration metabolism and balance the anaplerotic 470 reaction which feeds the TCA cycle.

471

472 Reference

473 1. Anjum SA, Ashraf U, Tanveer M, Khan I, Hussain S, Shahzad B, Zohaib A, Abbas F, Saleem 474 MF, Ali I, Long C, Wang LC. 2017. Drought induced changes in growth, osmolyte 475 accumulation and antioxidant metabolism of three maize hybrids. Frontiers in Plant Science $476 \quad 8: 69$

2. Asai S, Yoshioka M, Nomura H, Tone Ch, Nakajima K, Nakane E, Doke N, Yoshioka H. 2011. A plastidic glucose-6-phosphate dehydrogenase is responsible for hypersensitive response cell death and reactive oxygen species production. Journal of General Plant Pathology 77(3):152-162

3. Ashraf M, Harris PJC. 2004. Potential biochemical indicators of salinity tolerance in plants Plant Science 166(1):3-16

4. Bartels D, Dinakar C. 2013. Balancing salinity stress responses in halophytes and nonhalophytes: a comparison between Thellungiella and Arabidopsis thaliana. Functional Plant Biology 40(8):819-831

5. Bates LS, Waldren RP, Teare ID. 1973. Rapid determination of free proline for water-stress studies. Plant and Soil 39(1):205-207

6. Bechtold U, Pahlich E, Lea PJ. 1998. Methionine sulphoximine does not inhibit pea and wheat glutamate dehydrogenase. Phytochemistry 49(2):347-354 
490

491

492

493

494

495

496

497

498

499

500

501

502

503

504

505

506

507

508

509

510

511

512

513

514

515

516

517

518

519

520

7. Bowsher CG, Boulton EL, Rose J, Nayagam S, Emes MJ. 1992. Reductant for glutamate synthase is generated by the oxidative pentose phosphate pathway in non- photosynthetic root plastids. The Plant Journal 2(6):893-898

8. Bradford MM. 1976. A rapid and sensitive method for the quantitation of microgram quantities of protein utilizing the principle of protein-dye binding. Analytical Biochemistry $72(1-2): 248-254$

9. Canino S, Nieri B, Pistelli L, Alpi A, De Bellis L. 1996. NADP ${ }^{+}$-isocitrate dehydrogenase in germinating cucumber cotyledons: purification and characterization of a cytosolic isoenzyme. Plant Physiology 98(1):13-19

10. Cardi M, Chibani K, Castiglia D, Cafasso D, Pizzo E, Rouhier N, Jacquot J-P, Esposito S. 2013. Overexpression, purification and enzymatic characterization of a recombinant plastidial glucose-6-phosphate dehydrogenase from barley (Hordeum vulgare cv. Nure) roots. Plant Physiology and Biochemistry 73:266-273

11. Chen R. 1998. Plant NADP-dependent isocitrate dehydrogenases are predominantly localized in the cytosol. Planta 207(2):280-285

12. Chen R-D, and Gadal P. 1990. Do mitochondria provide the 2-oxoglutarate needed for glutamine synthesis in higher plant chloroplast? Plant Physiology and Biochemistry 28:141145

13. Corpas FJ, Barroso JB. 2014. NADPH-generating dehydrogenases: their role in the mechanism of protection against nitro-oxidative stress induced by adverse environmental conditions. Frontiers in Environmental Science. 2

14. Corpas FJ, Barroso JB. 2018. Peroxisomal plant metabolism - an update on nitric oxide, $\mathrm{Ca}^{2+}$ and the NADPH recycling network. Journal of Cell Science 131(2):1-8 doi: $10.1242 /$ jcs. 202978

15. Couee I, Sulmon C, Gouesbet G, El Amrani A. 2006. Involvement of soluble sugars in reactive oxygen species balance and responses to oxidative stress in plants. Journal of Experimental Botany 57(3):449-459

16. Coruzzi GM, Zhou L. 2001. Carbon and nitrogen sensing and signaling in plants: emerging 'matrix effects'. Current Opinion in Plant Biology 4(3):247-253

17. Cruz JL, Mosquim PR, Pelacani CR, Araújo WL, DaMatta FM. 2003. Carbon partitioning and assimilation as affected by nitrogen deficiency in cassava. Photosynthetica 41(2):201-207 
521 18. Debouba M, Gouia H, Suzuki A, Ghorbel MH. 2006. NaCl stress effects on enzymes involved

522 in nitrogen assimilation pathway in tomato Lycopersicon esculentum seedlings. Journal of 523 Plant Physiology 163(12):1247-1258.

524 19. Debouba M, Maâroufi-Dghimi H, Suzuki A, Ghorbel MH, Gouia H. 2007. Changes in growth 525 and activity of enzymes involved in nitrate reduction and ammonium assimilation in tomato 526 seedlings in response to $\mathrm{NaCl}$ stress. Annals of Botany 99(6):1143-51.

527 20. Degl'Innocenti E, Hafsi, C, Guidi L, Navari-Izzo F. 2009. The effect of salinity on 528 photosynthetic activity in potassium-deficient barley species. Journal of Plant Physiology 166: $529 \quad 1968-1981$.

530 21. de Sousa CA, Sodek L. 2003. Alanine metabolism and alanine aminotransferase in soybean 531 532 Glycine max. during hypoxia of the root system and subsequent return to normoxia. Environmental and Experimental Botany 50:1-8

22. Deuschle K, Funck D, Forlani G, Stransky H, Biehl A, Leister D, van der Graaff E, Kunze R, Frommer WB. 2004. The role of $\Delta^{1}$-pyrroline-5-carboxylate dehydrogenase in proline degradation. Plant Cell 16(12):3413-3425

23. Douce R, Neuburger M. 1989. The uniqueness of plant mitochondria. Annual Review of Plant Physiology and Plant Molecular Biology 40:371-414

24. Esposito S, Massaro G, Vona V, Di Martino Rigano V, Carfagna S, Rigano C. 2001. Ammonium induction of a novel isoform of glucose-6P dehydrogenase in barley roots. Plant Physiology 113(4):469-476

25. Fieuw S, Müller-Röber B, Gálvez S, Willmitzer L. 1995. Cloning and expression analysis of the cytosolic $\mathrm{NADP}^{+}$-dependent isocitrate dehydrogenase from potato. Implications for nitrogen metabolism. Plant Physiology 107(3):905-913.

26. Flores PM, Botella Á, Cerdá A, Martínez V. 2004. Influence of nitrate level on nitrate assimilation in tomato (Lycopersicon esculentum) plants under saline stress. Plant, Cell and Environment 82(2):207-213

27. Forde BG, Lea PJ. 2007. Glutamate in plants: metabolism, regulation, and signaling. Journal 549 of Experimental Botany 58(9):2339-2358

28. Fontaine J-X, Saladino F, Agrimonti C, Bedu M, Terce- Laforgue T, Tetu T, Hirel B, Restivo FM, Dubois F. 2006. Control of the synthesis and subcellular targeting of the two GDH gene 
551 products in leaves and stems of Nicotiana plumbaginifolia and Arabidopsis thaliana. Plant 552 and Cell Physiology 47(3):410- 418.

553 29. Foyer CH. 1988. Feedback inhibition of photosynthesis through source-sink regulation in 554 leaves. Plant Physiology and Biochemistry 26(4):483-492

555 30. Frechilla S, Lasa B, Aleu M, Juanarena N, Lamsfus C, Aparicio-Tejo PM. 2002. Short-term 556 ammonium supply stimulates glutamate dehydrogenase activity and alternative pathway 557 respiration in roots of pea plants. Journal of Plant Physiology 159(8):811-818

558 31. Gajewska E, Skłodowska M. 2009. Nickel-induced changes in nitrogen metabolism in wheat 559 shoots. Journal of Plant Physiology 166(10):1034-1044

560 32. Gálvez S, Gadal P. 1995. On the function of the NADP-dependent isocitrate dehydrogenase 561 in living organisms. Plant Science 105(1):1-14

562 33. Gálvez S, Lancien M, Hodges M. 1999. Are isocitrate dehydrogenases and 2-oxoglutarate 563 involved in the regulation of glutamate synthesis? Trends in Plant Science 4(12):484-490

564 34. Gibson SI. 2000. Plant sugar-response pathways. Part of a complex regulatory web. Plant 565 566 567 568 569 Physiology 124(4):1532-1539

35. Groat RG, Vance CP. 1981. Root nodule enzyme of ammonia assimilation in alfalfa (Medicago sativa L.). Developmental patterns and response to applied nitrogen. Plant Physiology 67(6):1198-1203

36. Gupta B, Huang B. 2014. Mechanism of salinity tolerance in plants: physiological, biochemical, and molecular characterization. International Journal of Genomics 1-19

37. Hachiya T, Sakakibara H. 2017. Understanding plant nitrogen metabolism through metabolomics and computational approaches. Journal of Experimental Botany 68(10):25012512

38. Hayat S, Hayat Q, Alyemeni MN, Wani AS, Pichtel J, Ahmad A. 2012. Role of proline under 576 changing environments. Plant Signaling and Behavior 7(11):1456-1466

39. Hellmann H, Funck D, Rentsch D, Frommer WB. 2000. Hyper- sensitivity of an Arabidopsis sugar signaling mutant toward exogenous proline application. Plant Physiology 122:357-367 ammonium assimilation. Journal of Experimental Botany 53(370):905-916 
580

581

582

583

584

585

586

587

588

589

590

591

592

593

594

595

596

597

598

599

600

601

602

603

604

605

606

607

608

609

610

41. Hodges M, Flesch V, Gálvez S, Bismuth E. 2003. Higher plant NADP+-dependent isocitrate dehydrogenases, ammonium assimilation and NADPH production. Plant Physiology and Biochemistry 41:577-585

42. Hossain Z, Mandal AK, Datta SK, Biswas AK. 2007. Development of NaCl-tolerant line in Chrysanthemum morifolium Ramat. through shoot organogenesis of selected callus line. Journal of Biotechnology 129:658-667

43. Jha AB, Dubey RS. 2004. Arsenic exposure alters activity behavior of key nitrogen assimilatory enzymes in growing rice plants. Plant Growth Regulation 43(3):259-268

44. Keunen E, Peshev D, Vangronsveld J, Ende W, Cuypers A. 2013. Plant sugars are crucial players in the oxidative challenge during abiotic stress: extending the traditional concept. Plant, Cell and Environment 36(7): 1242-1255

45. Kruger NJ, von Schaewen A. 2003. The oxidative pentose phosphate pathway: structure and organization. Current Opinion in Plant Biology 6(3):236-246

46. Kumar RG, Shah K, Dubey RS. 2000. Salinity induced behavioral changes in malate dehydrogenase and glutamate dehydrogenase activities in rice seedlings of differing salt tolerance. Plant Science 156:23-34.

47. Kwinta J, Koźlik D. 2006. Glutamine synthetase and glutamate dehydrogenase in cadmium stressed triticale seedlings. Acta Physiologiae Plantarum 28(4):339-347

48. Lasa B, Frechilla S, Asparcio-Tejo PM, Lamsfus C. 2002. Role of glutamate dehydrogenase and phosphoenolpyruvate carboxylase PEPC, activity in ammonium nutrition tolerance in roots. Plant Physiology and Biochemistry 40(11):969-976

49. Leterrier M, Barroso JB, Valderrama R, Palma JM, Corpas FJ. 2012. NADP-dependent isocitrate dehydrogenase from Arabidopsis roots contributes in the mechanism of defence against the nitro-oxidative stress induced by salinity. Scientific World Journal 2012:69477040.

50. Leterrier M, Barroso JB, Valderrama R, Begara-Morales JC, Sánchez-Calvo B, Chaki, M, Luque F, Viñegla B, Palma JM, Corpas FJ. 2016. Peroxisomal NADP-isocitrate dehydrogenase is required for Arabidopsis stomatal movement. Protoplasma 253:403-415.

51. Li D, Tian M, Cal J, Jiang D, Cao W, Dai T. 2013. Effects of low nitrogen supply on relationships between photosynthesis and nitrogen status at differential leaf position in wheat seedlings. Plant Growth Regulation 70(3):257-263 
611 52. Liu T, van Staden J. 2001. Partitioning of carbohydrates in salt-sensitive and salt-tolerant 612 soybean callus cultures under salinity stress and its subsequent relief. Plant Growth 613 Regulation 33(1):13-17

614 53. Liu Y, Shi Y, Song Y, Wang T, Li Y. 2010. Characterization of a stress-induced NADP615 isocitrate dehydrogenase gene in maize confers salt tolerance in Arabidopsis. Journal of Plant 616 Biology 53(2):107-112

617 54. Liu Y, von Wirén N. 2017. Ammonium as a signal for physiological and morphological 618 responses in plants. Journal of Experimental Botany 68(10):2581-2592

619 55. López-Bucio J, Nieto-Jacobo MF, Ramirez-Rodriguez V, Herrera-Estrella L. 2000. Organic 620 acid metabolism in plants: from adaptive physiology to transgenic varieties for cultivation in 621 extreme soils. Plant Science 160(1):1-3

622 56. Manai J, Gouia H, Corpas FJ. 2014. Redox and nitric oxide homeostasis are affected in tomato 623 (Solanum lycopersicum) roots under salinity-induced oxidative stress. Journal of Plant 624 Physiology 171:1028-35.

625 57. Martinez-Andújar C, Ghanem ME, Albacete A, Pérez-Alfocea F. 2013. Response to 626 nitrate/ammonium nutrition of tomato (Solanum lycopersicum L.) plant overexpressing a 627 prokaryotic $\mathrm{NH}_{4}^{+}$- dependent asparagine synthetase. Journal of Plant Physiology 170(1):676$628 \quad 867$

629

58. Masclaux C, Valadier MH, Brugiére N, Morot-Gaudry JF, Hirel B. 2000. Characterization of the sink/source transition in tobacco Nicotiana tabacum L. shoots in relation to nitrogen management and leaf senescence. Planta 211(4):510-518.

632

633

59. Miflin BJ, Habash DZ. 2002. The role of glutamine synthetase and glutamate dehydrogenase in nitrogen assimilation and possibilities for improvement in the nitrogen utilization of crops. Journal of Experimental Botany 53(370):979-987

60. Mhamdi A, Mauve C, Houda G, Saindrenan P, Hodges M, Noctor G. 2010. Cytosolic 636 NADP-dependent isocitrate dehydrogenase contributes to redox homeostasis and the regulation of pathogen responses in Arabidopsis leaves. Plant, Cell and Environment 33(7):1112-1123

61. Muchate NS, Nikalje GC, Rajurkar NS, Suprasanna P, Nikam TD. 2016. Plant salt stress: adaptive responses, tolerance mechanism and bioengineering for salt tolerance. Botanical Review 82(4):371-406 
642 62. Nunes-Nesi A, Araújo WL, Obata T, Fernie AR. 2013. Regulation of the mitochondrial 643 tricarboxylic acid cycle. Current Opinion in Plant Biology 16(3):335-343

644 63. Naliwajski MR, Skłodowska M. 2014. Proline and its metabolism enzymes in cucumber cell 645 cultures during acclimation to salinity. Protoplasma 251(1):201-209

646 64. Negrão S, Schmöckel SM, Tester M. 2017. Evaluating physiological responses of plants to 647 salinity stress. Annals of Botany 119(1): 1-11.

648 65. Nemoto Y, Sasakuma T. 2000. Specific expression of glucose-6-phosphate dehydrogenase 649 G6PDH gene by salt stress in wheat (Triticum aestivum L.) Plant Science 158(1-2):53-60.

650 66. Oliveira HC, Justino GC, Sodek L, Salgado I. 2009. Amino acid recovery does not prevent 651 susceptibility to Pseudomonas syringae in nitrate reductase double-deficient Arabidopsis 652 thaliana plants. Plant Science 176(1):105-117

653 67. Pérez-López U, Robredo A, Lacuesta M, Mena-Petite A, Muñoz-Rueda A. 2009 The impact 654 of salt stress on the water status of barley plants is partially mitigated by elevated CO2. 655 Environmental and Experimental Botany 66(3):463-470

656 68. Podgórska A, Gieczewska K, Łukawska K, Rasmusson AG, Gardeström P, Szal B. 2013. 657 Long-term ammonium nutrition of Arabidopsis increases the extra chloroplast $658 \mathrm{NAD}(\mathrm{P}) \mathrm{H} / \mathrm{NAD}(\mathrm{P})(+)$ ratio and mitochondrial reactive oxygen species level in leaves but 659 does not impair photosynthetic capacity. Plant, Cell and Environment 36(11):2034-2045

660 69. Reda M. 2015. Response of nitrate reductase activity and NIA genes expression in roots of 661 Arabidopsis hxk1 mutant treated with selected carbon and nitrogen metabolites. Plant Science $662 \quad 230: 51-58$

663 70. Rejšková A, Patková L, Stodůlková E, Lipavská H 2007. The effect of abiotic stresses on 664 carbohydrate status of olive shoots (Olea europaea L.) under in vitro conditions. Journal of 665 Plant Physiology 164(2):174-184

666 71. Roitsch T 1999. Source-sink regulation by sugar and stress. Current Opinion in Plant Biology $6672(3): 198-206$

668 72. Roychoudhury A, Banerjee A, Lahiri V. 2015. Metabolic and molecular-genetic regulation of 669 proline signaling and its cross-talk with major effectors mediates abiotic stress tolerance in 670 plants. Turkish Journal of Biology 39(6):887-910

671 73. Sami F, Yusuf M., Faizan M, Faraz A, Hayat S. 2016. Role of sugars under abiotic stress. 672 Plant Physiology and Biochemistry 109:54-61 
673 74. Sgherri C, Quartacci MF, Izzo R, Navari-Izzo F. 2002. Relation between lipoic acid and cell 674 redox status in wheat grown in excess copper. Plant Physiology and Biochemistry 40(6675 8):591-597

676

677

678

679

680

681

682

683

684

685

686

687

688

689

690

691

692

693

694

695

696

697

698

699

700

701

702

703

75. Signorelli S, Arellano JB, Melø TB, Borsani O, Monza J. 2013. Proline does not quench singlet oxygen: evidence to reconsider its protective role in plants. Plant Physiology and Biochemistry 64:80-83

76. Signorelli S, Coitiño EL, Borsani O, Monza J (2014) Molecular mechanisms for the reaction between $\mathrm{OH}$ radicals and proline: insights on the role as reactive oxygen species scavenger in plant stress. Journal of Physical Chemistry B 118:37-47.

77. Signorelli S, Imparatta C, Rodríguez-Ruiz M, Borsani O, Corpas FJ, Monza J. 2016. In vivo and in vitro approaches demonstrate proline is not directly involved in the protection against superoxide, nitric oxide, nitrogen dioxide and peroxynitrite. Functional Plant Biology 43(9) 870-879

78. Singh S, Srivastava PK. 2014. Purification and characterization of glucose-6-phosphate dehydrogenase from pigeon pea (Cajanus cajan) seeds. Advances in Enzyme Research 2(4):134-149

79. Singh M, Kumar J, Singh S, Singh V, Prasad S. 2015. Roles of osmoprotectants in improving salinity and drought tolerance in plants: a review. Reviews in Environmental Science and Bio/Technology 14(3):407-426

80. Sivritepe N, Sivritepe HÖ;;Türkan I, Bor M, Özdemir F. 2008. NaCl pre-treatments mediate salt adaptation in melon plants through antioxidative system. Seed Science and Technology 36(2) $360-370$

81. Snight BK. 1999. Plant amino acids. Biochemistry and biotechnology. New York: Marcel Dekker.

82. Szabados L, Savoure A. 2010. Proline: a multifunctional amino acid. Trends in Plant Scince 15:89-97.

83. Terce-Laforgue T, Dubois F, Ferrario-Mery S, Pou de Crecenzo MA, Sangwan R, Hirel B 2004. Glutamate dehydrogenase of tobacco is mainly induced in the cytosol of phloem Valderrama photorespiration. Plant Physiology 136(4):4308-4317

84. Tercé-Laforgue T, Bedu M, Dargel-Grafin C, Dubois F, Gibon Y, Restivo FM, Hirel B. 2013. Resolving the role of plant glutamate dehydrogenase: II. Physiological characterization of 
704 plants overexpressing the two enzyme subunits individually or simultaneously. Plant Cell 705 Physiology 54(10):1635-47.

706 85. Touraine B, Muller B, Grignon C. 1992. Effect of phloem-translocated malate on $\mathrm{NO}_{3}$ uptake 707 by roots of intact soybean plants. Plant Physiology 99(3):1118-1123

708 86. Valderrama R, Corpas FJ, Carreras A, Gómez-Rodríguez MV, Chaki M, Pedrajas JR, 709 Fernanadez-Ocańa A, del Rio LA, Barroso JB. 2006. The dehydrogenase-mediated recycling 710 of NADPH is a key antioxidant system against salt-induced oxidative stress in olive plants. 711 Plant, Cell and Environment 29(7):1449-1459

712 87. van Dongen JT, Gupta KJ, Ramírez-Aguilar SJ, Araüjo WL, Nunes-Nesi A, Fernie AR. 2011. 713 Regulatory of respiration in plants: A role for alternative metabolic pathways. Journal of Plant 714 Physiology 168(12):1434-1443

715 88. Wang M, Shen Q, Xu G, Guo S. 2014. New insight into the strategy for nitrogen metabolism in plant cells. International Review of Cell and Molecular Biology 310:1-37

89. Zhang D, Liang N, Shi A., Liu L, Chen J, Du G. 2009. Enhanced of $\alpha$-ketoglutarate production in Torulopsis glabrata: redistribution of carbon flux from pyruvate to $\alpha$-ketoglutarate. Biotechnology and Bioprocess Engineering 14(2):134-139

90. Zhang L, Liu J, Wang X, Bi Y. 2013. Glucose-6-phosphate dehydrogenase acts as a regulator of cell redox balance in rice suspension cells under salt stress. Plant Growth Regulation 722 69:139-48 
Figure 1 (on next page)

Changes in aminating glutamate dehydrogenase (NADH-GDH) (a) and deaminating glutamate dehydrogenase ( $\mathrm{NAD}^{+}-\mathrm{GDH}$ ) (b) activities in cucumber leaves in plants treated with 100 and $150 \mathrm{mM} \mathrm{NaCl}$ : non-acclimated (NAP) and acclimated (AP) to salinization

Bars represent SD of means, $n=4$. * indicate a significant difference between NAP and AP; or NAP, NAP-100 and NAP-150; or AP, AP-100 and AP-150 

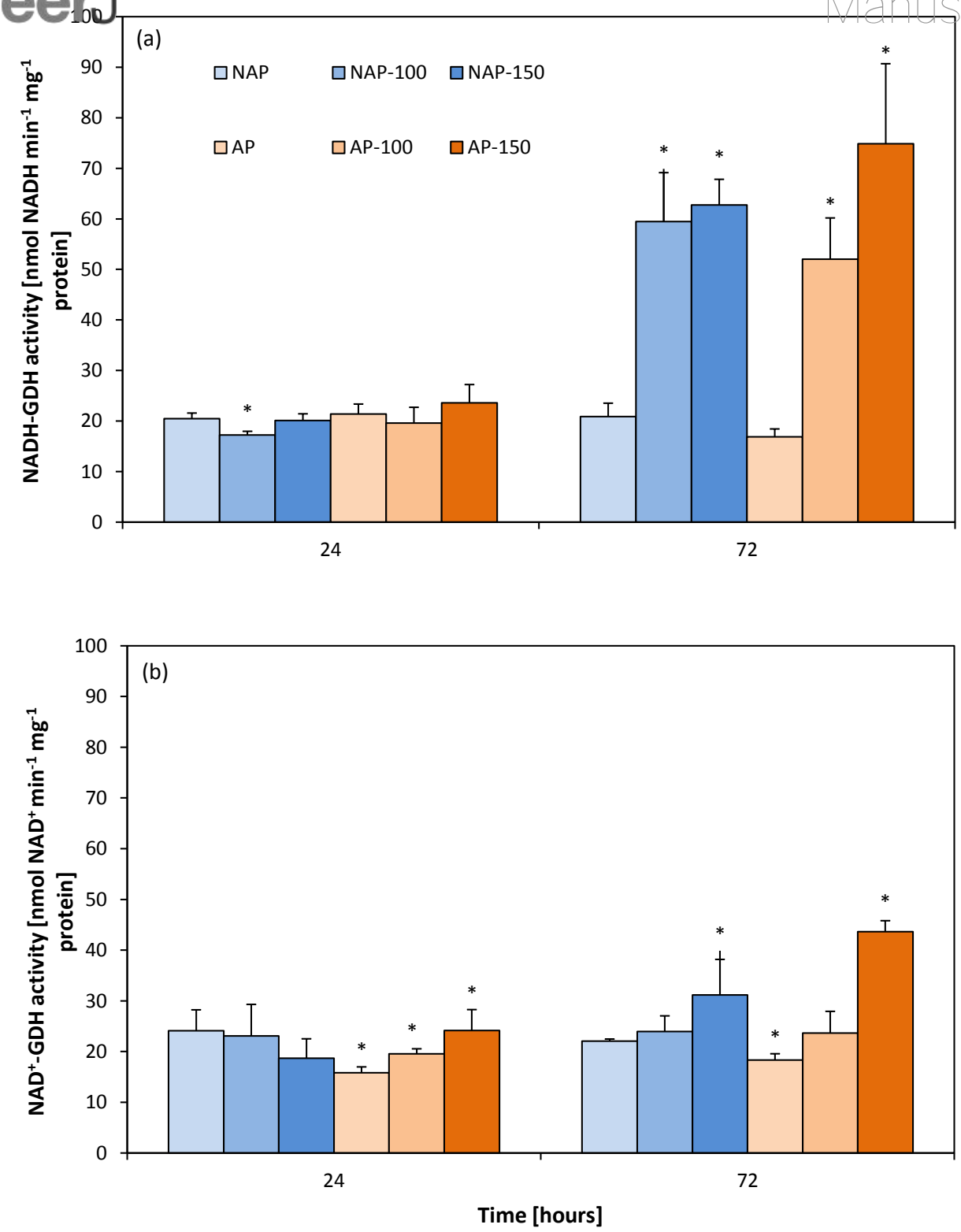


\section{Figure 2 (on next page)}

Changes in alanine aminotransferase (AlaAT) (a) and asparate aminotransferase (AspAT) (b) activities in cucumber leaves in plants treated with 100 and $150 \mathrm{mM} \mathrm{NaCl}$ : non-acclimated (NAP) and acclimated (AP) to salinization.

Bars represent SD of means, $n=4$. * indicate a significant difference between NAP and AP; or NAP, NAP-100 and NAP-150; or AP, AP-100 and AP-150 

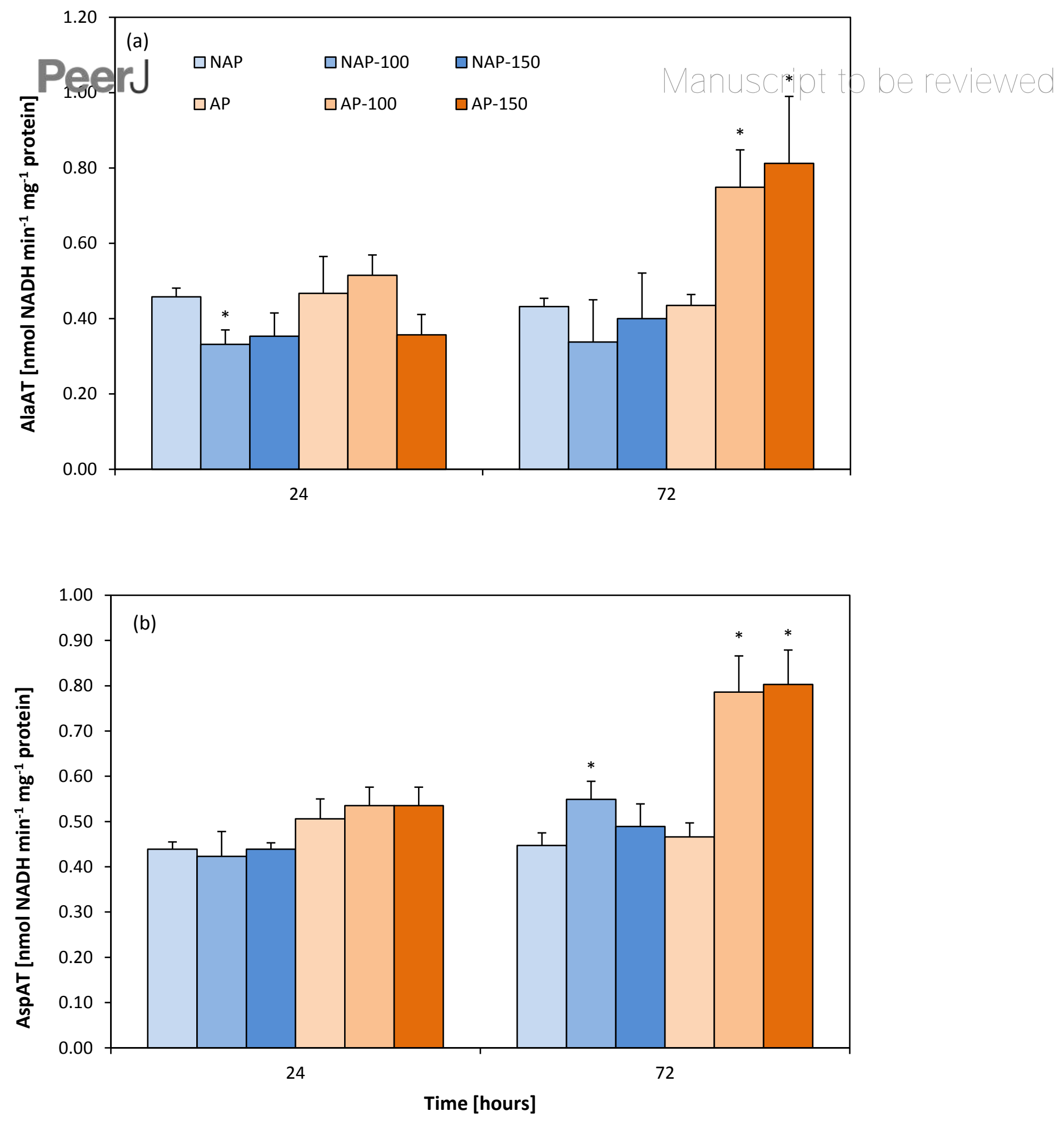
Figure 3 (on next page)

Changes in 6-phosphogluconate dehydrogenase (6PGDH) (a), glucose-6-phosphate dehydrogenases (G6PDH) (b) and NADP+-isocytrate dehydrogenases activity (NADP+$\mathrm{ICDH}$ ) (c) activities in cucumber leaves in plants treated with 100 and $150 \mathrm{mM} \mathrm{NaCl}$ : non-acclimated

Bars represent SD of means, $n=4$. * indicate a significant difference between NAP and AP; or NAP, NAP-100 and NAP-150; or AP, AP-100 and AP-150 

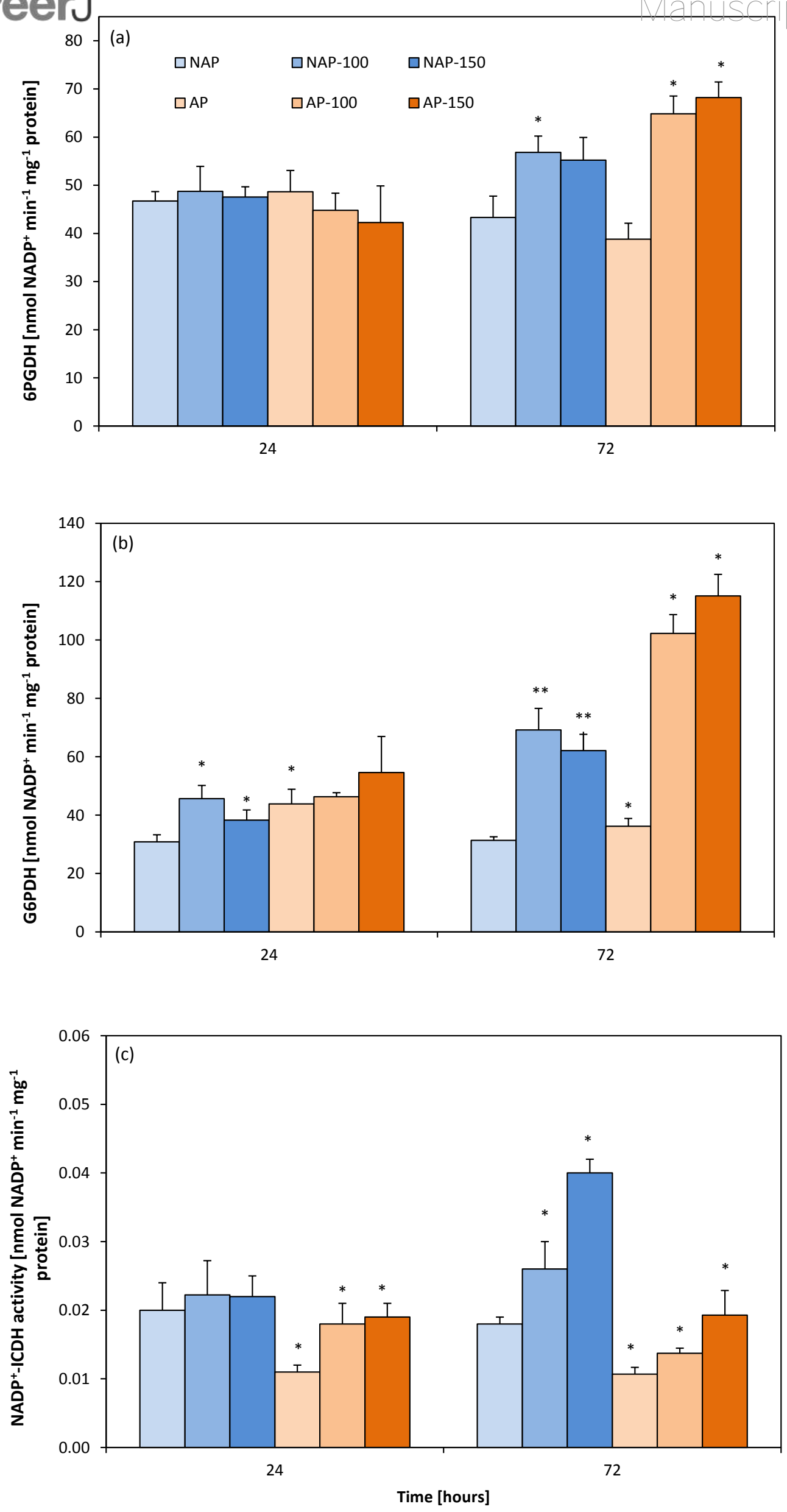


\section{Figure 4(on next page)}

Changes in glucose (a), sucrose (b) and proline (c) concentrations in cucumber leaves in plants treated with 100 and $150 \mathrm{mM} \mathrm{NaCl}$ : non-acclimated (NAP) and acclimated (AP) to salinization.

Bars represent SD of means, $n=4$. * indicate a significant difference between NAP and AP; or NAP, NAP-100 and NAP-150; or AP, AP-100 and AP-150 

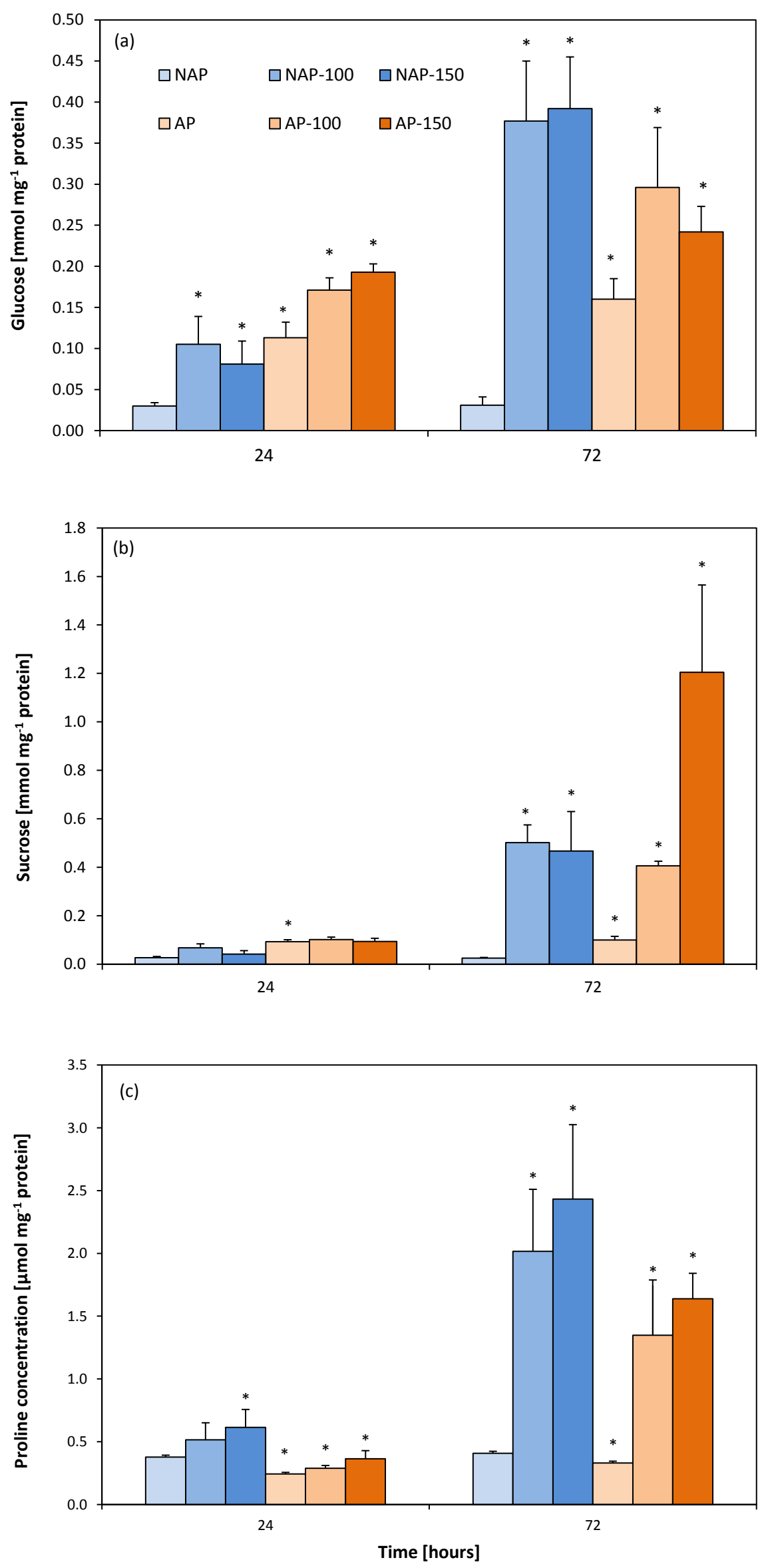


\section{Figure 5}

Effect of salt stress treatment on the morphology of non-acclimated cucumber plants. NAP - non-acclimated plant, NAP-100 - non-acclimated plant stressed with $100 \mathrm{mM}$ $\mathrm{NaCl}, \mathrm{NAP}-150$ - non-acclimated plant stressed with $150 \mathrm{mM} \mathrm{NaCl}$ 


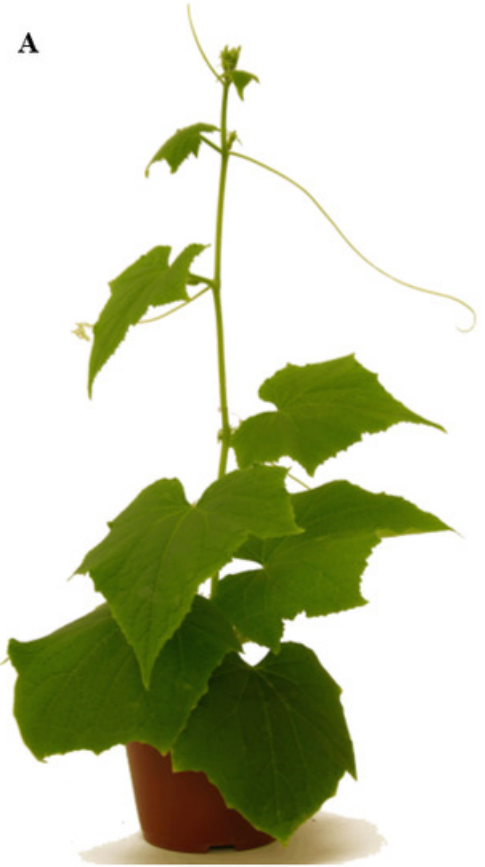

NAP $-24 h$

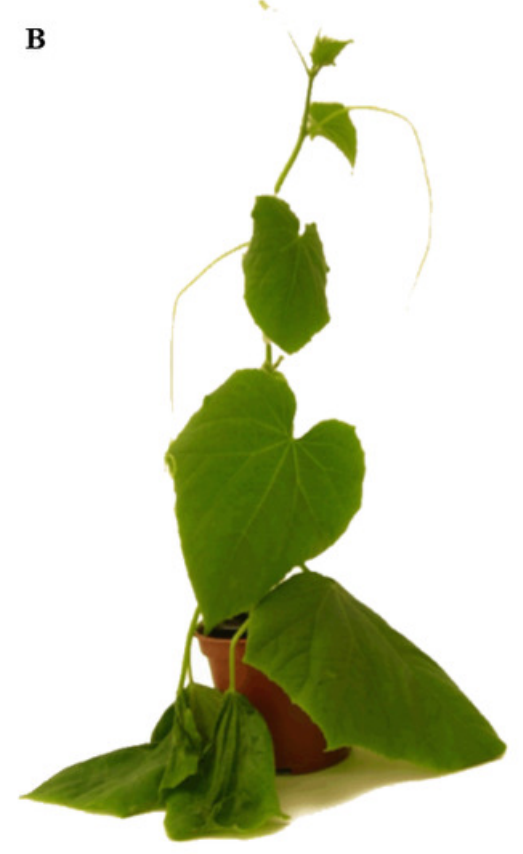

NAP-100 - 24h

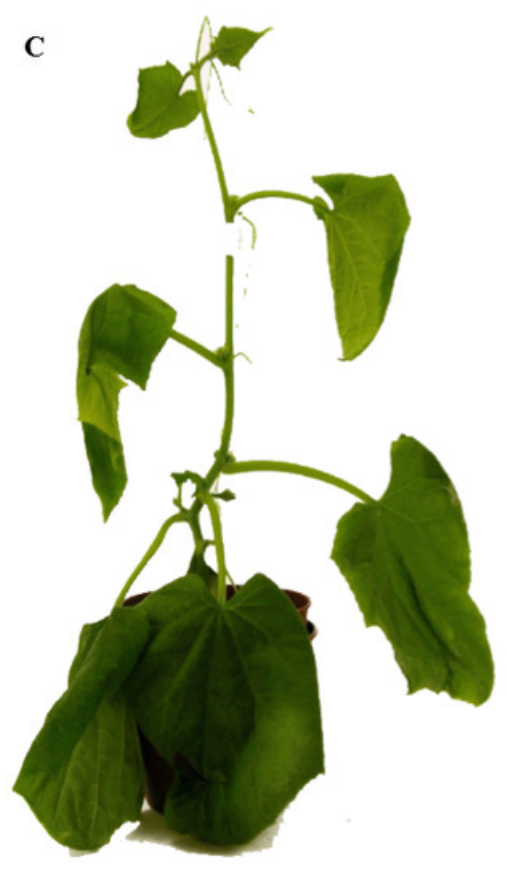

NAP-150-24h

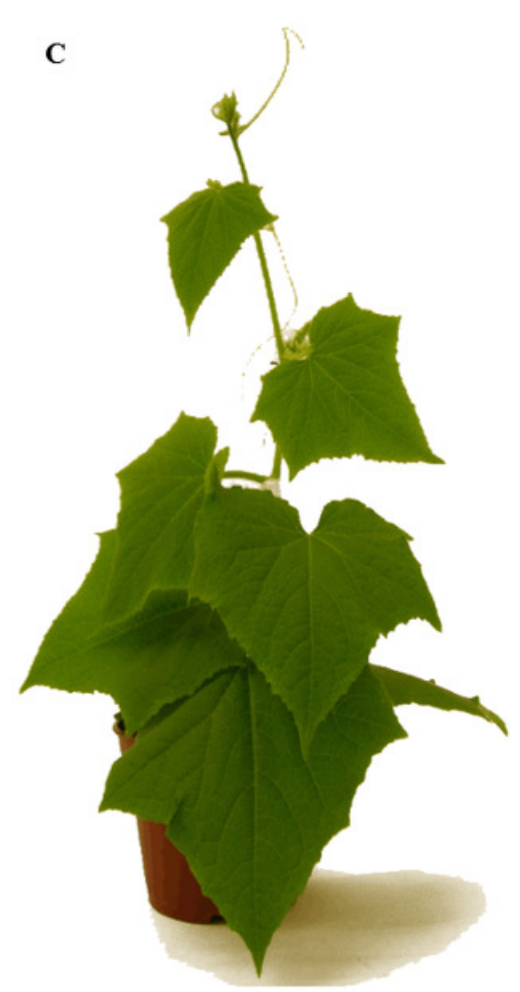

NAP $-72 h$

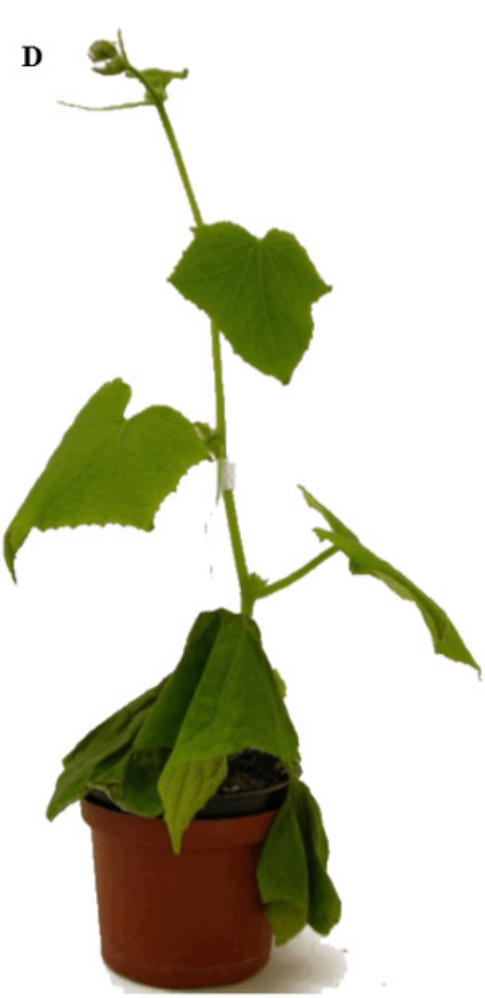

NAP-100-72h

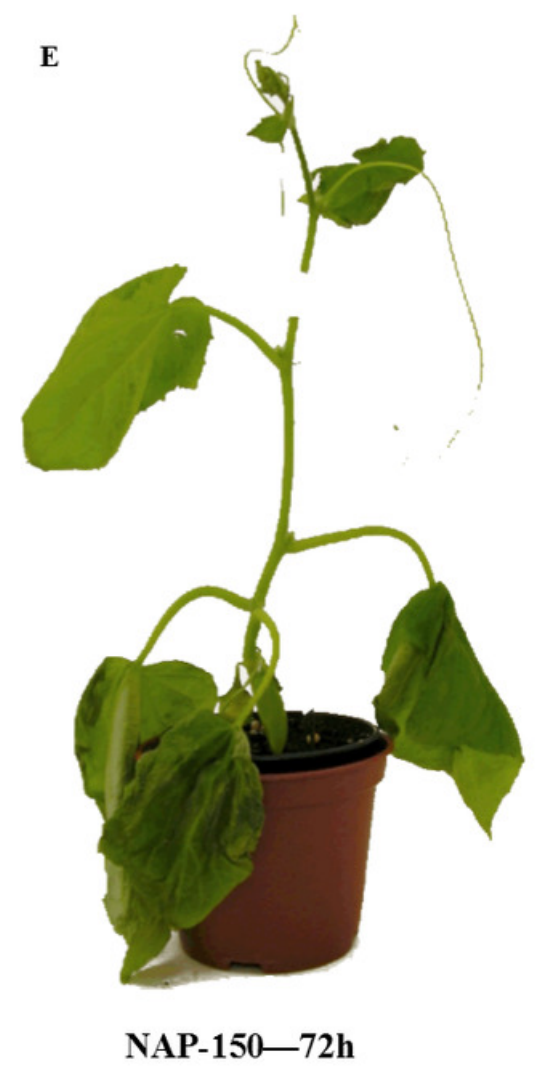


Figure 6

Effect of salt stress treatment on the morphology of acclimated cucumber plants. AP acclimated plant, AP-100 -acclimated plant stressed with 100 mM NaCl, AP-150 - nonacclimated plant stressed with $150 \mathrm{mM} \mathrm{NaCl}$ 


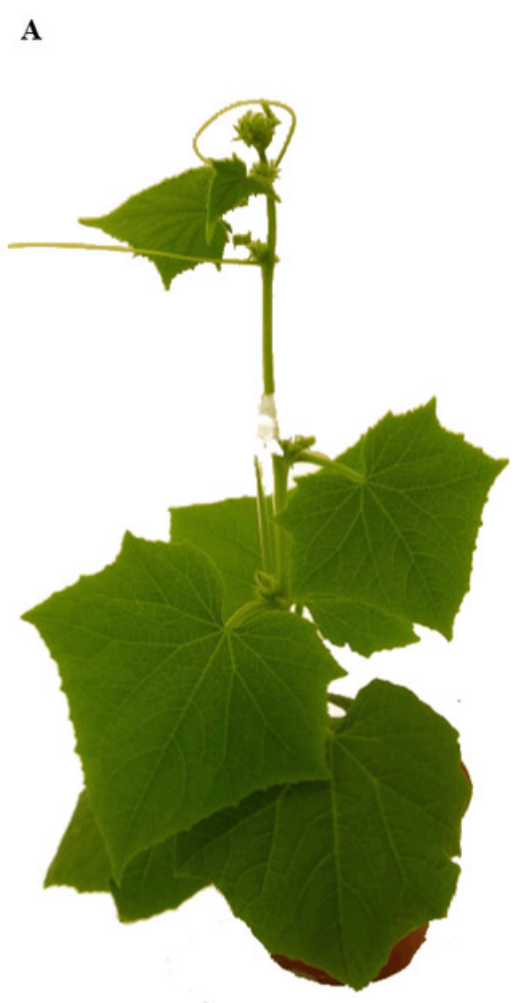

AP-24h

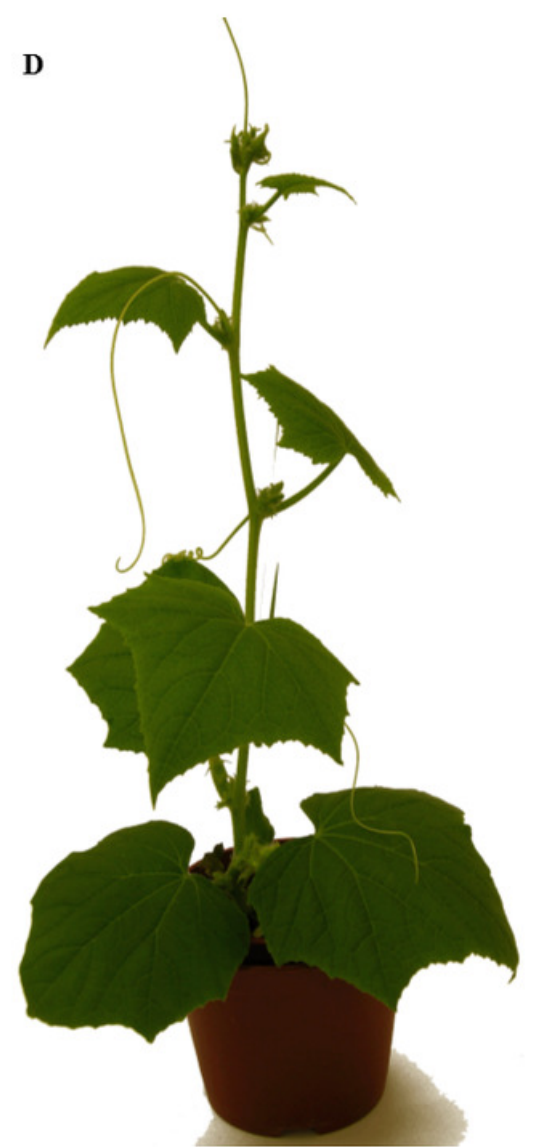

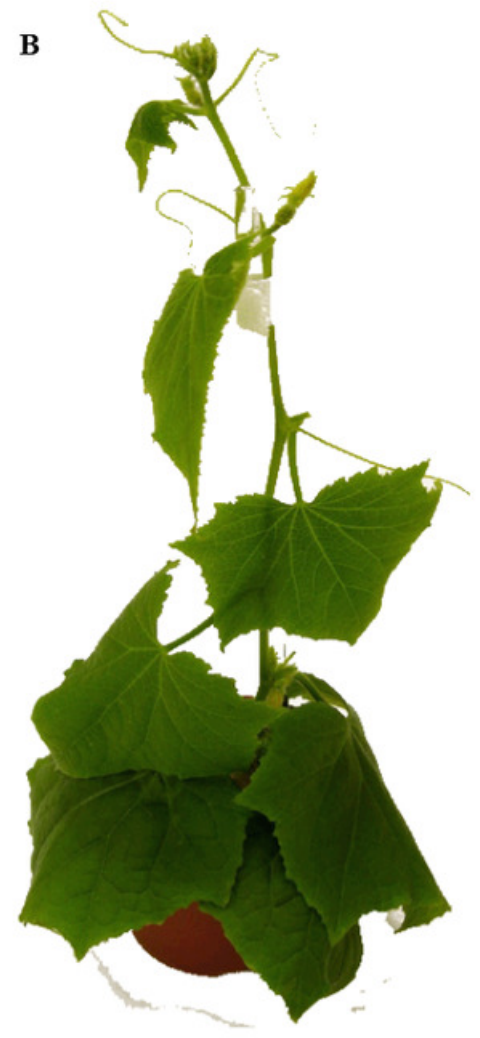

AP-100-24h

E

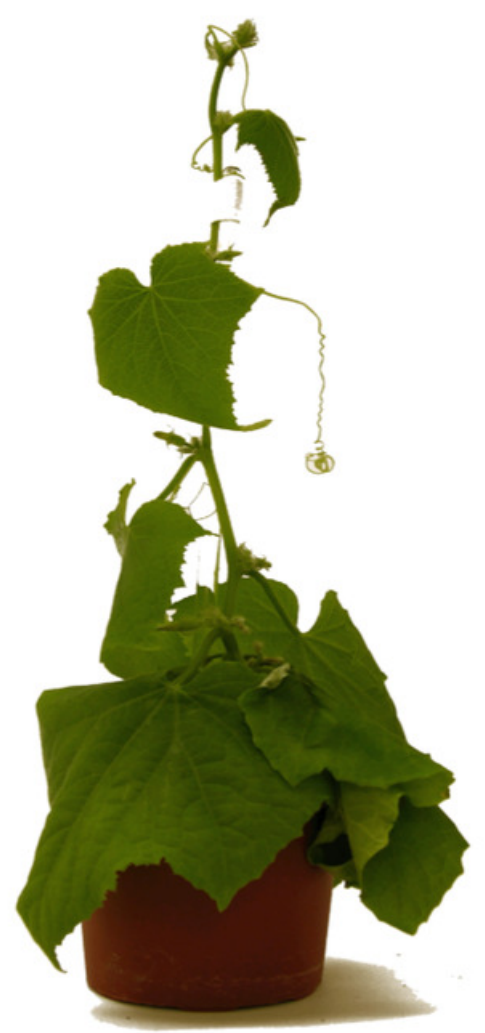

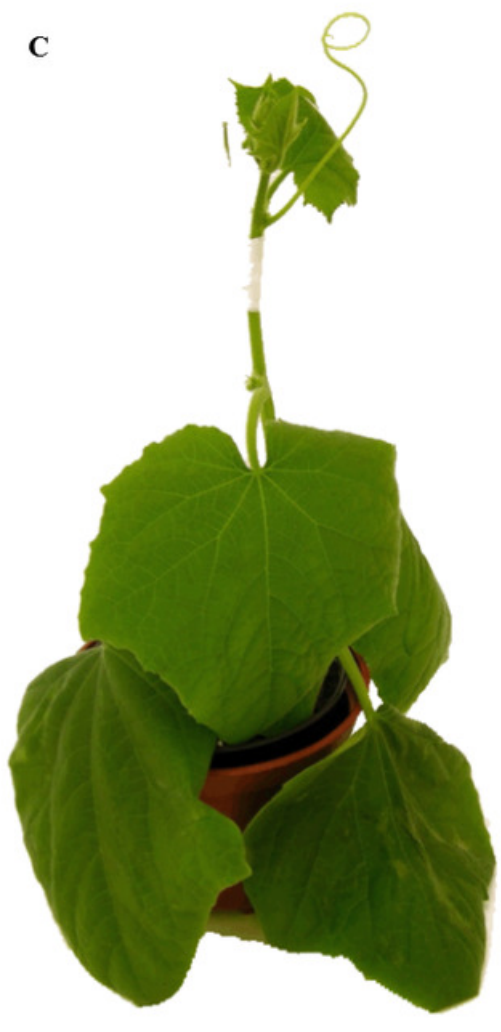

AP-150-24h

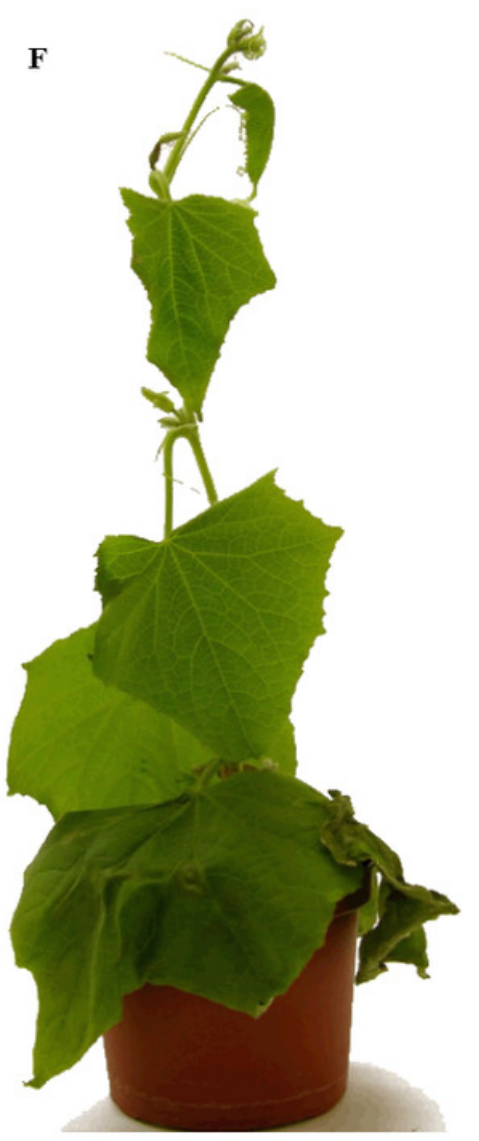

AP-150-72h 